\title{
Protesta social y derecho: una tensión irresoluble
}

\author{
Social protest and law: an irresolvable tension
}

\author{
Jaime Bassa Mercado* - Daniel Mondaca Garay ${ }^{* *}$
}

\begin{abstract}
Resumen: Este artículo analiza la tensión producida por el encuentro entre constitucionalismo y protesta social y cómo esta tensión se manifiesta al problematizar la reciente doctrina del derecho a la protesta social. Los autores sostienen que existe una distancia irreductible entre estos fenómenos, pues dado que la protesta opera fuera del ámbito de la normatividad, el Derecho parece insuficiente para procesar la protesta social como fenómeno sociopolítico. Para ilustrar lo anterior, expondrá la insuficiencia de la libertad de expresión como piedra angular de la protesta social y se examinarán las tensiones entre lo individual y colectivo que implican los actos de protesta social.
\end{abstract}

Palabras clave: constitucionalismo, protesta social, libertad de expresión, conflicto social.

\begin{abstract}
This paper analyses the tension produced by the encounter between constitutionalism and social protest, and how this tension appears upon problematizing the recent doctrine of social protest. Authors acknowledge an irreducible distance between these two phenomenons, due to the fact that social protest exists outside of the borders of legal normativity, hence, the legal system appears insufficient to process social protest as a socio-political phenomenon. In order to illustrate this main argument, it will expose the frailty of free speech clause as a cornerstone for social protest, as well as the tensions between both the individual and collective elements that constitute acts of social protest.
\end{abstract}

Key Words: constitutionalism, social protest, free speech clause, social conflict.

Recibido: 12 abril 2018 Aceptado: 6 julio 2018

\footnotetext{
* Doctor en Derecho, Universidad de Barcelona. Magíster en Filosofía, Universidad de Valparaíso. Profesor titular de Derecho Constitucional y de Teoría Política. Investigador del Centro de Estudios Interdisciplinarios en Teoría Social y Subjetividad (CEI-TESys), Universidad de Valparaíso, Chile. Av. Errázuriz 2120, Valparaíso, Chile. Correo electrónico: jaime.bassa@uv.cl, jbassa@gmail.com

** Licenciado en Derecho, Universidad Central de Chile. Magíster en Derecho Público, Universidad de Valparaíso. Profesor de Derecho Constitucional, Universidad de Valparaíso. Correo electrónico: dmondacagaray@gmail.com
} 


\section{Introducción}

En los últimos años, el fenómeno de la protesta social ha protagonizado una intensa revisión de los elementos fundamentales del ordenamiento jurídico vigente, especialmente en lo que se refiere a la forma en que se reconocen, protegen y garantizan ciertos derechos fundamentales. En este contexto, la reciente doctrina del derecho a la protesta constituye una novedosa tendencia destinada a procesar la movilización social en el lenguaje jurídico, mediante su identificación como un derecho expresivo y la yuxtaposición a otros derechos constitucionales, tales como el derecho de reunión y de petición. Sin embargo, pese a la actualidad de esta reflexión jurídica, ella no encuentra un correlato congruente en otras disciplinas de las ciencias sociales que se han dedicado al estudio de la movilización social, tales como la sociología y la teoría política. Mientras en el Derecho prevalece una vinculación de la protesta con la libertad de expresión como marco metodológico para su estudio, en la sociología se destacan otros elementos de la protesta que desbordan la cláusula constitucional de expresión y que dicen relación con la materialización del conflicto y de la movilización social como ejercicio político.

Desde esa perspectiva, se presentarán los puntos problemáticos de esta nueva doctrina del derecho a protestar, para lo cual revisaremos los conceptos capitales de la protesta, tanto en el Derecho como en la sociología, para contrastarlos entre sí y revisar su congruencia. Veremos los problemas a los que se enfrenta el Derecho para entregar un tratamiento a la protesta social y cómo la libertad constitucional de expresión se presenta, a priori, como una categoría acertada para vincular la protesta al derecho, pero que evidencia sus limitaciones cuando los principios troncales del constitucionalismo son puestos en diálogo con las nociones básicas de la protesta, tales como el conflicto social, el antagonismo político y la acción política colectiva desinstitucionalizada.

Creemos que la protesta no puede ser procesada por el Derecho, que se debe limitar a reconocer que esta opera en un ámbito ajeno a lo normativo, uno que evidencia cómo la sociedad interpela y transforma al Derecho en tanto ciencia social, ya no normativa. Así, la protesta no es, simplemente, un derecho, sino una práctica política y social que no puede ser categorizada dentro de los límites que impone el aparato teórico de los derechos fundamentales: un individualismo liberal.

Desde la importancia de analizar cómo el constitucionalismo puede ser problematizado al encontrarse con la protesta, proponemos que este encuentro está marcado por una tensión irresoluble que se manifiesta en construcciones políticas que persiguen finalidades distintas: por un lado, el constitucionalismo que necesita de un consenso político en torno a valores y principios que pretenden vincular a toda la sociedad $\mathrm{y}$, por el otro, la protesta que aparece como un ejercicio político de la sociedad que tiende a desbordar la pretensión meramente expresiva y que, en ocasiones, no reclama del Derecho su protección, sino más bien lo impugna para conseguir su transformación.

En primer lugar, haremos una breve descripción del derecho a la protesta en la doctrina, identificando sus basamentos teóricos y describiendo sus justificaciones constitucionales; en la segunda parte, buscaremos problematizar la doctrina del derecho a la protesta, analizando los atolladeros que presenta ante las regulaciones neutrales de la 
protesta. Luego, revisaremos las dificultades que suponen las nociones de lo individual y lo colectivo en un eventual derecho subjetivo a protestar, para finalmente indagar en los límites epistémicos de la libertad de expresión como matriz de significación preferente para la comprensión de la protesta social. Presentamos este trabajo como un ejercicio de pensamiento en el límite 1 , donde los basamentos del constitucionalismo pueden desdibujarse y facilitar la emergencia de lecturas alternativas en torno al fenómeno constitucional, surgiendo nuevas interrogantes respecto de la matriz ideológica de este discurso y sobre cómo responde el sistema institucional a la política ejercida por otros medios.

\section{La doctrina del derecho a la protesta social}

Durante muchos años, la protesta social fue un tema ajeno a los debates constitucionales. Era vista como un fenómeno metajurídico y sus justificaciones teóricas, principalmente sociológicas y politológicas, no encontraban eco desde el Derecho. Sin embargo, a partir de las movilizaciones sociales verificadas en Estados Unidos de América desde la década de 1960, la protesta social comenzó a ocupar un lugar en la jurisprudencia norteamericana delineándose, a partir de ésta, una serie de precedentes judiciales que resaltaban su vinculación con la libertad constitucional de expresión. De este lado del hemisferio, el Derecho Constitucional permaneció impermeable a esta nueva tendencia jurídica y la respuesta institucional frente a la movilización social fue siempre la misma: el uso de la herramienta penal para reestablecer el orden público y perseguir responsabilidades ulteriores. Sin embargo, el surgimiento de diversas protestas sociales en el contexto de las democracias latinoamericanas durante las décadas de 1990 y 2000 obligó al Derecho Constitucional latinoamericano a prestar atención a estas manifestaciones políticas, surgiendo una doctrina que propone entender la protesta social como un derecho y enfatizando su compatibilidad con el régimen constitucional democrático, a partir de una lectura más abierta sobre el contenido de la libertad de expresión y su rol para escrutar a la autoridad y reclamar necesidades insatisfechas.

La doctrina del derecho a la protesta social asienta sus bases en la apelación a diversas nociones jurídicas y políticas presentes en el desarrollo del constitucionalismo; lo que se quiere es acercar la protesta al derecho sugiriendo que esta no es ajena a las discusiones que han acompañado el devenir jurídico y que sus vinculaciones son más notorias de lo que se cree. Así, Gargarella sostiene que la protesta social puede vincularse a nociones politológicas de larga data, como la idea de resistencia a la autoridad presente en las primeras meditaciones del derecho natural sobre el ejercicio del poder político. Para Gargarella, esta antigua idea de resistir y desobedecer a la autoridad ilegítima e injusta, presente en el corazón del constitucionalismo, permitiría afirmar que la desobediencia y la resistencia al derecho no son, a priori, conductas reprochables y antijurídicas. Para Gargarella, hay circunstancias en que el derecho "no representa una expresión más o menos fiel de nuestra voluntad como comunidad sino que se presenta como un conjunto de normas ajenas a nuestro designio y control, que afecta a los intereses básicos de una

${ }^{1}$ MILLAS Jorge, Filosofía del Derecho, Santiago, Ediciones UDP, 2012, 102. 
mayoría de la población, pero frente al cual ésta aparece sometida"2. En tales casos nos encontraríamos frente a una situación de "alienación legal", un sometimiento de la población a un orden jurídico que atenta contra sus intereses más básicos, que permite actualizar la vieja noción de resistencia a la autoridad al proponer que los actos de protesta social pueden manifestar episodios de resistencia constitucional, los cuales "se distinguen por la presencia de violaciones del derecho positivo, que pueden asumir un carácter violento, destinadas a frustrar leyes, políticas, o decisiones del gobierno de turno"3. Por otra parte, Gargarella sostiene que fuera de los basamentos teóricos del constitucionalismo, la protesta social también encuentra su correlato en otras nociones más actuales de la filosofía del derecho, como por ejemplo en la noción de desobediencia civil desarrollada latamente en el derecho a partir del trabajo del trabajo de autores como John Rawls y Ronald Dworkin.

A su vez, la protesta social ha sido especialmente observada desde la óptica de la libertad de expresión 4 . Sus componentes expresivos, que movilizan críticas políticas y divulgan ideas, son evidentes, por lo que concebir a la protesta como una forma de ejercicio de la libertad de expresión ha sido la piedra angular para construir este derecho a protestar. Sus rendimientos como vehículo de ideas y reclamos son especialmente útiles para grupos o sectores de la sociedad que, en razón dicha situación de alienación legal al no tener acceso a los medios de comunicación masivos para expresar sus reclamos. Así, la protesta social se transforma en la única herramienta de comunicación efectivamente accesible para importantes sectores de la sociedad.

Como podrá observarse, la reciente atención del derecho constitucional por la protesta social sigue las metodologías usuales en la creación doctrinal, tratando de aglutinar un conjunto de reflexiones en un solo cuerpo de ideas que sirvan de referencia para el tratamiento de la protesta como fenómeno social mediado por el Derecho. Este constructo del derecho a la protesta social presenta grandes diferencias con el desarrollado estudio que la sociología ha realizado de la protesta social y que ha permitido oxigenar otras materias adyacentes, tales como el estudio sobre los movimientos sociales o la teoría del conflicto, entre otras. La revisión sociológica de la protesta se caracteriza por su diversidad de aproximaciones, al punto que puede afirmarse que -a diferencia de la pretensión del Derecho por delinear una doctrina unificada a partir de la libertad de

2 GARGARELLA Roberto, El derecho a la protesta. El primer derecho, Buenos Aires, Editorial Ad Hoc, $2007,205$.

3 GARGARELLA, Ibid, 207.

4 A este respecto destacan los trabajos de GARGARELLA, op. cit, y GARGARELLA Roberto, Carta abierta sobre la intolerancia. Apuntes sobre derecho y protesta, Buenos Aires, Siglo XXI, 2015. Asimismo, puede observarse como esta doctrina ha orientado otras opiniones jurídicas que destacan el carácter expresivo de la protesta social. Lo anterior puede observarse en el trabajo de la Relatoría Especial para la Libertad de Expresión de la Comisión Interamericana de Derechos Humanos, en el informe del año 2010 denominado "Una agenda hemisférica para la defensa de la libertad de expresión", en el cual señala: "La protesta social es una de las formas colectivas más eficaces de expresión. Pero incluso, en algunas circunstancias resulta ser también la única forma a través de la cual ciertos grupos pueden ser escuchados. En efecto, cuando se está frente a marcos institucionales que no favorecen la participación, o frente a serias barreras de acceso a formas más tradicionales de comunicación de masas, la protesta pública parece ser el único medio que realmente permite que sectores tradicionalmente discriminados o marginados del debate público puedan lograr que su punto de vista resulte escuchado y valorado". 
expresión- opta por un análisis casuístico, al asumir que este fenómeno está determinado por factores económicos, sociales y políticos que responden al contexto en que la protesta emerge y se desarrolla 5 . Ello hace imposible la formulación de algo así como una teoría general de la protesta social.

Ahora bien, más allá de la particularidad que caracteriza a los actos de protesta social, la sociología ha podido reconocer fenómenos que están envueltos en la movilización social y que dicen relación con la materialización del conflicto. Así, Diani y Della Porta comprenden, en los siguientes términos, la conflictividad como un rasgo distintivo de la acción colectiva de los movimientos sociales: "By conflict we mean an oppositional relationship between actors who seek control of the same stake -be it political, economic, or cultural power- and in the process make negative claims on each other -i.e., demands which, if realized, would damage the interests of the other actors" 6 . Un criterio compartido en la sociología política indica que el conflicto es consustancial a la convivencia social, por lo que no es visto como algo negativo o perjudicial, sino que implica reconocer el dinamismo de la sociedad y la existencia de diferencias y desacuerdos en los distintos espacios de convivencia. En este sentido, lo pernicioso del conflicto estaría más bien vinculado a sus efectos y formas de solución antes que a su mera aparición. A partir de allí, entonces, es posible comprender a la protesta como un fenómeno que desborda la dimensión expresiva que el derecho constitucional sugiere y, así, avanzar en una significación política de la protesta como una "la lucha abierta entre grupos sociales opuestos [que] tendrá un nivel ideológico-cultural, caracterizado por la valoración que se haga de la situación preexistente y, por extensión, de las expectativas de cada grupo, y otro nivel de acción social, concretado en los repertorios tácticos empleados, en las formas de acción colectiva, y en la tipología general de los conflictos sociales"7. Es así que la protesta social se desenvuelve como una herramienta contenciosa, táctica, estratégica, conflictiva y antagónica, cuestión que pone en tensión la comprensión consensualista de la política que ha condicionado la reflexión constitucional.

\section{Dificultades para construir un derecho a la protesta social}

\section{Las regulaciones neutrales de la protesta social}

Uno de los dispositivos más destacables de la propuesta de Gargarella, mediante el cual sugiere una compatibilidad de la protesta con el derecho, es el rescate de la doctrina del tiempo, lugar y modo, o, time, place and manner restrictions. La premisa de la protesta como derecho supone someterla al estándar similar al de otros derechos y, desde luego, examinar cómo un eventual derecho a la protesta puede ser moderado a fin de que su ejercicio no perturbe derechos de otras personas o valores relevantes jurídicamente. Así,

\footnotetext{
5 SCRIBANO Adrián, "Reflexiones sobre una estrategia metodológica para el análisis de las protestas sociales", en Sociologías, ( $N^{\circ}$ 9, 2003), 64-104.

6 DELLA PORTA, Donatella; DIANI, Mario, Social movements. An introduction, Oxford, Blackwell Publishing, 2006, 21.

7 LORENZO CADARSO, Pedro: Fundamentos teóricos del conflicto social, Madrid, Siglo XXI, 2001, 12.
} 
en su texto "Un diálogo sobre la protesta social y la ley", Gargarella rescata la doctrina del tiempo, lugar y modo para retrucar a quienes muestran quejas sobre la forma en que los manifestantes llevan a cabo sus protestas y exigen que estas sean moderadas y razonables8; en definitiva, que no perturben los intereses de terceros ${ }^{9}$. Esta doctrina, asentada en la jurisprudencia de la Suprema Corte de los Estados Unidos de América, se ha desarrollado a partir de casos en donde se han presentado conflictos que involucran la colisión de la cláusula de la libertad de expresión, reconocida en la primera enmienda de la Constitución norteamericana, que señala: “Congress shall make no law respecting an establishment of religion, or prohibiting the free exercise thereof; or abridging the freedom of speech, or of the press; or the right of the people peaceably to assemble, and to petition the Government for a redress of grievances" 10 .

La Suprema Corte ha determinado que la manifestación social no es sino un derecho expresivo, compatible con la libertad de expresión individual y protegida bajo la garantía de la primera enmienda. Para hacer esto posible, desarrolló la doctrina del foro público, que supone afirmar que la manifestación social no puede ser la materialización de un derecho expresivo individual ilimitado y que debe supeditarse a las regulaciones específicas que tienen los espacios públicos y el tipo de propiedad que recae sobre estos. En este sentido, ha reconocido la facultad de la Administración para establecer regulaciones específicas en torno a la protesta, autorizando al gobierno para establecer condiciones en cuanto al tiempo en que se realiza la protesta, a los lugares escogidos para realizarla y a los modos en que se expresa.

Si bien no hay acuerdo al origen de esta doctrina, el caso Hague v. CIO ha sido identificado como la punta de lanza a la hora de referirse a la libertad de expresión como protesta social11. Dicho caso enfrentó a Frank Hague, alcalde de New Jersey durante 1939, con Committe for Industrial Organization, CIO, integrada por sindicatos de trabajadores

\footnotetext{
8 Sobre la necesidad de la moderación en la protesta, si bien la cuestión de la violencia es un elemento de constante referencia en la reflexión jurídica sobre la protesta social, es necesario señalar que no se aprecia un estudio detallado sobre esta; por el contrario, se la asume como un fenómeno negativo bajo cualquier circunstancia. Aquello es, desde luego, una patente debilidad analítica pues, a pesar de que el derecho la conciba como ilegítima a todo evento, la sociología ha sido enfática en señalar que la violencia es un fenómeno que no admite ser englobado en una única concepción. Por el contrario, resulta una necesidad estudiarla a partir de los contextos históricos y, sobre todo, según el tipo de actividad en que esta es utilizada. En este orden de ideas, no es lo mismo decir Golpe de Estado que decir huelga; rebelión que asesinato. Cualquier intención de unificar la violencia a partir de una valoración negativa incondicionada resulta no sólo un sinsentido, sino una debilidad teórica insalvable. Ahora bien, como advierte GONZÁLEZ CALLEJA, el pensamiento jurídico "examina a la violencia en relación a los criterios normativos vigentes dentro de un grupo social concreto, basados en los valores y creencias asumidos como propios por la mayoría de la comunidad en un momento histórico determinado", y es por ello que en el pensamiento jurídico "la asimilación de violencia con el caos, la anarquía, el desorden, la transgresión, la irracionalidad y la ausencia de normas o de formas sociales ha sido aceptada en ocasiones de manera excesivamente conformista por los estudiosos del fenómeno", GONZÁLEZ CALLEJA Eduardo, Asalto al poder. La violencia política organizada y las ciencias sociales, Madrid, Siglo XXI, 2017, 37-40.

9 GARGARELLA Roberto, “Un diálogo sobre la protesta social y la ley”, en Revista de la Facultad de Derecho (No 61, 2008) Lima, Pontificia Universidad Católica del Perú, 19-50.

10 Primera enmienda a la Constitución de los Estados Unidos de América (1791).

11 O’NEILL Kevin, “Disentangling the law of public protest”, en Loyola Law Review (Vol. 45, 1999), Chicago, 411-526.
} 
industriales. Hague dictó una ordenanza que prohibía a los trabajadores reunirse en espacios públicos y distribuir panfletos vinculados a su organización. El caso fue conocido por la Corte de distrito y posteriormente por la Suprema Corte, que falló a favor de los trabajadores, determinando que la ordenanza vulneraba la primera enmienda y el derecho de reunión ${ }^{12}$.

A partir de Hague v. CIO, la Suprema Corte resolvió diversos casos en donde colisionaban la libertad de expresión de los ciudadanos con las potestades de la autoridad para mantener el orden público, delineándose una doctrina que es conocida al día de hoy como time, place and manner restrictions. Dicho cuerpo de ideas viene a reconocer que la autoridad está facultada para establecer limitaciones a la protesta, entendida esta como materialización de la libertad de expresión, distinguiendo el grado e intensidad de las restricciones admisibles según el lugar en que se desarrolla la manifestación ${ }^{13}$.

Los principios básicos de esta doctrina señalan la idea que la protesta como libertad de expresión debe ser unida a la noción del public fora, es decir, los foros públicos que son utilizados para manifestarse y del tipo de propiedad que recae sobre estos foros públicos. Desde luego, una de las cuestiones a menudo omitidas en las lecturas actuales sobre la protesta social, es que la Suprema Corte viene a autorizar las restricciones a la protesta no sólo porque reconoce que la libertad de expresión no puede ser ilimitada, sino también en razón de la especial consideración que tiene respecto del impacto de la protesta en la propiedad de aquellos lugares donde se realiza dicha actividad, cuestión que pone en relieve la tensa relación protesta/propiedad y que no ha sido lo suficientemente abordada en la doctrina sobre el derecho a la protesta. Así, para dar forma a las restricciones admisibles a la protesta en relación a su impacto en los foros públicos, la Suprema Corte propuso una distinción tripartita:

En primer lugar, reconoció la existencia de foros públicos o traditional public fora, que son sitios tradicionalmente identificados como lugares de reunión y en que se han llevado a cabo mítines para la divulgación de ideas y de expresión en general. Estos foros públicos son espacios tradicionales como plazas, aceras o parques. Lo importante es que la Suprema Corte los ha reconocido como los espacios usuales de reunión y expresión para quienes no tienen acceso a otros canales de expresión y, junto con esto, ha determinado que los gobiernos federales no pueden cerrar estos espacios, pero que pueden establecer regulaciones razonables para su uso: "may be regulated only via content-neutral time,

\footnotetext{
12 Suprema Corte de los Estados Unidos de América, 307 U.S. 496 (1939), Hague v. Committee for Industrial Organization.

13 En Chile, esta comprensión de las limitaciones a la protesta ha sido recibida por LOVERA: “Desde un punto de vista sustantivo debemos dar una vuelta más larga. En primer lugar, cabe advertir que estas regulaciones no son inconstitucionales en sí mismas -aunque su ejercicio puede llegar a serlo. Tanto en el derecho internacional de los derechos humanos como en el derecho comparado, las regulaciones tipo manera, tiempo y lugar (MTL) de las protestas son adecuadas considerando que las autoridades deben crearse una idea de las medidas que deben tomar (por ejemplo, cómo reordenar el flujo de tránsito) para lograr que las movilizaciones se desarrollen tan libre de problemas como sea posible, así como para salvaguardar los derechos de terceras personas y de los mismos manifestantes". LOVERA, Domingo, “Libertad de expresión, derecho de reunión y protesta en la Constitución", en La Constitución chilena. Una revisión crítica a su práctica política, Santiago, Lom, 2015, 99-119.
} 
place, and manner restrictions"14. Estas regulaciones (pretendidamente) neutrales de tiempo, lugar y modo son sometidas al judicial scrutiny, considerando que, para ser aprobadas judicialmente, deben estar "justified without reference to the content of the regulated speech; narrowly tailored to serve a significant governmental interest; and must leave open ample alternative channels for communication of the information" 15 .

Estas restricciones usualmente reciben el scrutiny más riguroso, toda vez que lo que está en juego, a juicio de la Suprema Corte, es la cláusula de la libertad de expresión de la primera enmienda. Así, en el caso de los foros públicos tradicionales, para que la regulación de tiempo, lugar y modo supere el control judicial esta debe ser neutral, lo que significa que debe ser aplicada equitativamente a todas las expresiones por igual, sin distinguir un grupo de otros. Además, las restricciones deben servir a un interés gubernamental significativo $\mathrm{y}$, por último, debe dejar abiertos otros canales de comunicación e información.

En segundo lugar, en los foros públicos limitados o designated public fora, las facultades del gobierno para regular son más amplias, pues se trata de lugares que, al mismo tiempo de ser de uso público, han sido dispuestos por el Estado para servir preferentemente a otros fines, tales como los juzgados, servicios públicos, universidades, entre otros. Se trata de espacios donde la libertad de expresión individual confluye con otros fines igualmente importantes. Lo interesante es que la Suprema Corte también ha entendido que estos lugares pueden ser foros públicos en la medida que la autoridad los abra para tal efecto: "are places that the government has opened for expressive activity by part or all of the public"16.

Esta comprensión evidencia las dificultades propias de pretender limitar la protesta dentro de los márgenes del Derecho: no nos parece razonable que una protesta, a menudo dirigida en contra de la autoridad, se encuentre supeditada a su voluntad para abrir lugares a los protestantes.

Finalmente, en el caso de los foros no-públicos o Non public fora, las facultades de regulación son más amplias aún, pues se trata de lugares destinados, en su mayoría, para fines distintos de la libertad de expresión individual. Así, en el caso Clark v. Community for Creative Non Violence, la Suprema Corte confirmó una regulación estatal que prohibía acampar en parques nacionales como una forma de expresión que pretendía simbolizar la situación de las personas sin hogar. La regulación federal tenía por objeto proteger el medio ambiente, pues se estimaba que el ejercicio expresivo de los manifestantes a través de sus campings producía daños en el parque, de modo que la Suprema Corte estimó que los manifestantes podían ejercer su libertad de expresión en otros lugares, sin que aquello fuese una limitación arbitraria a la libertad de expresión ${ }^{17}$.

La doctrina del tiempo, lugar y modo se ha mantenido con buena salud en el debate norteamericano, debido a la importancia sideral de la cláusula de la libertad de

14 O'NEILL, Ibid, 420.

15 Suprema Corte de los Estados Unidos de América, 491 U.S. 781 (1989), Ward v. World Against Racism.

16 Suprema Corte de los Estados Unidos de América, 515 U.S. 753 (1995), Capitol Square Review and Advisory Bd. v. Pinette.

17 Suprema Corte de los Estados Unidos de América, 468 U.S. 288 (1984), Clark v. Community for Creative Non Violence 
expresión en su tradición constitucional ${ }^{18}$. Muchos son los autores que han enfatizado la importancia que ha tenido la cláusula de la libertad de expresión en la historia de los Estados Unidos. Ha sido uno de los principios que han inspirado el desarrollo de un debate público robusto en grandes áreas, que hasta el día de hoy se mantiene como uno de los pilares del sistema constitucional norteamericano. Gargarella recurre a esta gran influencia de la primera enmienda para su propuesta de la protesta social como un derecho; sin embargo, el recurso al derecho comparado supone importantes desafíos desde la perspectiva metodológica, especialmente cuando la concepción norteamericana de la libertad de expresión se ha construido en base a la propia historia de dicho país, que desde luego presenta grandes diferencias de los países de Latinoamérica. Que los sistemas constitucionales latinoamericanos reconozcan la libertad de expresión no parece ser una causal suficiente para trasladar la comprensión norteamericana de la protesta social: no hay base empírica suficiente para afirmar que, frente al conflicto social, las instituciones Latinoamericanas actuarían de la misma forma que las estadounidenses.

Ahora bien, si se abandona la concepción expresiva de la protesta y se observan los puntos nodales de la acción colectiva de protesta social descrita por la sociología, podrá advertirse que, generalmente, la protesta se articula al margen de las posibilidades que el sistema institucional entrega $y$, al mismo tiempo, prescinde de las categorías prefiguradas por el derecho. Ella pretende ser una acción con una finalidad política que se desenvuelve estratégicamente, presionando a la autoridad con el objeto de alcanzar su cometido: "el cambio social, la creación-recreación del lazo social, no necesita ni articulacióncentralización ni unificación. Más aún, el cambio social emancipatorio va a contrapelo del tipo de articulación que se propone desde el Estado-academia-partidos"19.

Es en este punto donde la doctrina del tiempo, lugar y modo entra aún más en tensión: si la protesta social se articula en contra de la autoridad, no es posible aceptar que sea esa propia autoridad que fije no sólo los límites de la protesta, sino también las maneras en que esta debe expresarse. Desde luego, se podría argumentar que la doctrina del tiempo, lugar y modo tiene por objeto juzgar la proporcionalidad de las restricciones dispuestas por la autoridad más que las limitaciones impuestas a los protestantes. Sin embargo, por razonables que sean las limitaciones, existe un conflicto de difícil resolución si se acepta que la autoridad puede regular -aunque sea del modo menos intrusivo- una protesta dirigida precisamente en contra de ella. Ello nos presenta una cuestión de teoría política más sustantiva: el doble compromiso del constitucionalismo con el ideal de autodeterminación colectiva y de resistencia a la autoridad, por un lado; y con la limitación de la agencia política popular para garantizar la estabilidad de la autoridad como único camino posible de organización política, por el otro.

Ahora bien, si sólo cabe reconocer a la protesta como libertad de expresión, aquello debería implicar dos cuestiones: $i$. si la protesta es libertad de expresión, la autoridad no debería sentirse presionada o incómoda por su ejercicio y, ii. los manifestantes tampoco deberían sentirse agraviados por restricciones a su protesta, con tal que queden abiertos

18 FISS Owen, Democracia y Disenso. Una teoría de la libertad de expresión, Buenos Aires, Editorial Ad Hoc, 2010.

19 ZIBECHI Raúl, Dispersar el poder. Los movimientos como poderes antiestatales, Santiago, Editorial Quimantú, 2007. 
otros canales para expresar sus consignas. Como se ve, el discurso constitucional, fiel a este doble compromiso, ofrece una salida en que ambas partes deberían sentirse ganadoras: una mantiene el orden y la otra puede expresarse. Se trata, en definitiva, de una solución ficticia que contribuye a mantener viva la tensión entre protesta y constitución, pues no es del todo cierto que los ciudadanos se conformen sólo con expresarse. Sin embargo, es posible comprender la protesta como una forma desintitucionalizada de acción política, que pretende articular una práctica de resistencia contrahegemónica frente a las injusticias estructurales sostenidas, entre otros pilares, por el propio sistema constitucional, pues sus prácticas disruptivas no buscan sólo expresar algo sino presionar a la autoridad en determinada materia. Desde esta perspectiva, la categoría de la libertad de expresión resulta insuficiente para explicar este fenómeno social, lo que invita a realizar un trabajo analítico diferente, al margen del paradigma de los derechos individuales ${ }^{20}$.

En Chile, las protestas sociales de los últimos años han revitalizado el debate público, forzando a la autoridad a hacerse cargo de asuntos públicos urgentes. Un examen de los actos de protesta permite afirmar que buena parte de ellas han sido acciones radicales y contenciosas (tomas de escuelas y universidades, huelgas de hambre en recintos penitenciarios, paralización de servicios públicos, etc.), que difícilmente gozarían de una protección semejante a la primera enmienda. En 2006, cuando se llevó a cabo la denominada Revolución Pingüina, las formas más usuales de acción política fueron sucesivas protestas estudiantiles, mediante paros y tomas de escuelas públicas y privadas; tal fue el impacto de dichas protestas que causaron la salida del Ministro de Educación de la época y motivaron el inicio de un intenso debate público sobre el sistema de educación, que se extiende hasta nuestros días. En este sentido, parece evidente que $i$. el impacto y efectividad de aquellas protestas habría sido menor si hubiesen estado sujetas y controladas a las regulaciones de tiempo, lugar y modo, y ii. dichas formas de acción política no habrían encontrado protección en la garantía constitucional de la libertad de expresión. Desde luego, la propia Corte Suprema de los Estados Unidos ya había dado respuesta a esta interrogante en el caso Cox v. Lousiana: "Nor could one, contrary to traffic regulations, insist upon a street meeting in the middle of Times Square at the rush hour as a form of freedom of speech or assembly"21.

En otro caso más reciente, la Corte de Apelaciones de Santiago resolvió un conflicto suscitado entre la Municipalidad de Santiago y un grupo de apoderados del Instituto Nacional, quienes interpusieron una acción de protección con el objeto de impugnar un protocolo de movilización acordado entre un grupo de estudiantes movilizados y la autoridad de la comuna de Santiago, cuyo objeto era fijar reglas y criterios para el desarrollo de paros y tomas como forma de protesta estudiantil. La Corte de Santiago acogió el recurso, razonando sobre los límites de la libertad de expresión en los siguientes términos: "En un Estado de Derecho como el que rige en nuestro país la libertad de expresión está garantizada, pero como todo derecho tiene límites, resultando obvio que en uso de ella no se puede imponer medidas de fuerza sino que debe canalizarse por otros

20 LORENZO, Ibid, 167.

21 Suprema Corte de los Estados Unidos de América, 379 U.S. 536 (1965), Cox v. Lousiana. 
medios en ejercicio de esa y otras garantías que el orden institucional permite; así en ejercicio de la libertad de reunión los estudiantes pueden organizar marchas y jornadas de reflexión, en uso del derecho de opinión hacer declaraciones públicas, en ejercicio del derecho de petición formular demandas estudiantiles a la autoridad, etc., pero nunca recurrir a actos de fuerza que no pueden tener lugar en una sociedad democrática que se precie de tal" 22 .

Sin perjuicio de las objeciones a la forma en que la Corte de Santiago comprende la libertad de expresión, es necesario hacer notar que, al tiempo que repugna la toma como forma de protesta, ofrece canales alternativos y propone formas y modos para el ejercicio de la libertad de expresión. Así, resulta paradójico que uno de los fallos más conservadores del último tiempo recoja la doctrina más progresista del debate constitucional sobre la protesta, como es la doctrina del tiempo, lugar y modo. Más aún, el motivo del conflicto es precisamente la existencia de lo que pretende ser una regulación neutral de la protesta, como lo es un protocolo entre la autoridad y los estudiantes que fija criterios para el desarrollo de la protesta estudiantil. Lo paradójico, entonces, es que una regulación neutral de la protesta modelada desde la sede jurisdiccional ofreció mayores perspectivas para la neutralización del conflicto que garantías para los sujetos movilizados.

En otras palabras, la doctrina de la regulación neutral de la protesta, defendida como una herramienta para la protección de la protesta, opera al mismo tiempo como un instrumento para su neutralización, al repugnar las formas más intensas de movilización y reconociendo sólo aquellas que recurren a medios más moderados frente a la autoridad.

La efectividad de la protesta social se pierde si se ve obligada a un desarrollo moderado, compatible con el estándar jurídico de las regulaciones de tiempo, lugar y modo; dicho de otra forma, si los modos, tiempos y lugares de la protesta no logran incomodar a la autoridad, ¿tendría la protesta la capacidad suficiente para alcanzar la satisfacción de necesidad sociales que se estiman urgentes y que dependen, precisamente, de la voluntad política del gobernante?

Si la concepción norteamericana de la libertad de expresión fuese traslada a este país, y las formas locales de protesta quedasen sometidas a estándares judiciales o regulaciones administrativas, la protesta se transformaría en un ejercicio testimonial, que sólo serviría para vehiculizar la libertad de expresión y confiar en el responsiveness de la autoridad 23 .

\footnotetext{
22 Corte de Apelaciones de Santiago, Rol No 39022-2014, 18 de agosto de 2014.

23 "Los últimos estudios sobre las estrategias de lucha de los movimientos sociales, centrados en el periodo contemporáneo, han demostrado cómo el empleo de tácticas disruptivas, provocadoras, que renuncian a seguir los cauces legales o éticamente establecidos resultan beneficiosas a menudo para el movimiento, entre otras, por las siguientes razones: $a$. La existencia de un ala radical dentro del movimiento, que ejecuta este tipo de tácticas, mejora la imagen de los sectores moderados del mismo y fomenta actitudes negociadoras de las autoridades hacia ellos. Se produce, además, un desplazamiento general de las bases del conflicto hasta punto que, en origen, hubiesen sido considerados como radicales incluso por sectores mayoritarios del movimiento; $b$. Las formas de lucha ilegales focalizan la atención de las autoridades, de la opinión pública y de los medios de comunicación hacia la movilización, obligando a las autoridades a tomar decisiones al respecto e introduciendo los problemas que han provocado la movilización entre los asuntos de debate público.
} 
La realidad y formas de protesta latinoamericanas no pueden ser homologadas a la historia política de los Estados Unidos y sus formas jurídicas. Desde 1803, el sistema de judicial review norteamericano permite, a cualquier persona, reclamar la inconstitucionalidad de una ley, lo que en un sistema judicial de precedentes dota a las sentencias de una importancia política mucho mayor que en el sistema chileno, en donde las sentencias, además de tener ordinariamente efectos inter partes, no son vinculantes para otros tribunales ni para futuras decisiones. Las movilizaciones de protesta en Estados Unidos a menudo son acompañadas por acciones judiciales destinadas a derogar leyes que producen los efectos propios de la alienación legal. En Chile, la derogación de una ley vigente no es resorte de la jurisdicción constitucional, salvo en casos muy excepcionales. Es decir, esos canales de participación utilizados por la jurisprudencia y doctrina norteamericana para defender la idea de la protesta supeditada al derecho, no existen en este país. De este modo, cualquier posibilidad de una protesta juridificada sería funcional a los efectos de la incomunicación institucional denunciada por Gargarella, en la medida que, al desbordar los estándares de la protesta regulada, los grupos vulnerables serían fácilmente acallados.

Seguidamente, es necesario preguntarse sobre la legitimación para definir las regulaciones de tiempo, lugar y modo. Nuevamente se presentan dos salidas opuestas, pues la autoridad querrá siempre una protesta que no genere problemas y pueda ser rápidamente controlada; por su parte, los grupos movilizados querrían formas y acciones de protesta que puedan hacer frente al control estatal y que mejor sirvan para presionar a la autoridad, tales como las tácticas disruptivas a las que se hizo referencia.

Aunque la propuesta de Gargarella es pionera en una comprensión afable sobre el fenómeno social de la protesta, esta también tensiona la propia garantía de la movilización social. En efecto, la doctrina del tiempo, lugar y modo, que Gargarella rescata de la jurisprudencia de la Corte Suprema de los Estados Unidos, introduce un problema de difícil solución: aun cuando se proponga la comprensión de la protesta a partir del lenguaje de los derechos y, en particular, de sus límites, el efecto es perjudicial para la protesta social, puesto que la sola idea de una protesta supeditada o juzgada conforme a algún estándar jurídico, es una protesta juridificada y, por tanto, susceptible de ser neutralizada por la autoridad facultada para la aplicación del Derecho.

\section{Lo individual y lo colectivo en el derecho a la protesta}

Uno de los campos donde el discurso liberal ha devenido en hegemónico (Gramsci ${ }^{24}$ ) es en los derechos fundamentales. Es un hecho notorio que las discusiones más sofisticadas en teoría de los derechos constitucionales recogen diversas reflexiones morales y políticas de cuño liberal; ello no sólo puede constatarse en la literatura especializada, sino también en los órganos oficiales, mediante sentencias y declaraciones que reafirman

Evidentemente, éste es más un fenómeno contemporáneo que un concepto susceptible de aplicarse de manera generalizada"; LORENZO, Ibid,166.

24 GRAMSCI Antonio, Antología, Madrid, Akal, 2015. 
esta matriz política como la única posible para la democracia actual ${ }^{25}$. El discurso hegemónico ha enfatizado lo individual al pensar los derechos, lo que, para el caso de la protesta, presenta algunos inconvenientes.

El fundamento teórico más contundente del derecho a la protesta social ha sido proporcionado desde la libertad de expresión norteamericana, que reafirma la dimensión individual como parte del núcleo central del supuesto derecho a protestar, prescindiendo de la dimensión colectiva que envuelve toda protesta. Esta postergación del componente colectivo propio a la protesta se verifica en el papel secundario que estas doctrinas asignan al derecho de reunión en su configuración. Esto puede explicarse, en parte, por la dificultad del liberalismo de comprender la dimensión relacional asociativa ${ }^{26}$ propia de las acciones de protesta, puesto que los patrones compartidos y las decisiones colectivas no han formado parte de la reflexión liberal, reconduciendo todo lo políticamente relevante al ámbito individual del sujeto titular de derechos. Así, en la doctrina norteamericana la protesta social no es más que la agregación de individuos titulares de derechos, dejando de lado aspectos fundamentales de la protesta social, como los lazos y responsabilidades comunes, las orgánicas construidas mancomunadamente y olvidando que su propia finalidad se verifica colectivamente 27 . Aquello ha llevado a autores afines a la comprensión norteamericana a afirmar que la protesta puede ser objeto de una regulación más o menos blanda y, al mismo tiempo, que es posible castigar individualmente a los sujetos que protestan: "el reproche particular a quien comete un delito específico (acto de violencia

$25 \mathrm{Al}$ respecto puede verse PISARELLO Gerardo, Un largo termidor. Historia y crítica del constitucionalismo antidemocrático, Quito, Corte Constitucional para el Período de Transición, 2012; y ELSTER Jon y SLAGSTAD Rune, Constitucionalismo y democracia, México D.F., Editorial Fondo de Cultura Económica, 1999.

26 A este respecto puede consultarse la lectura de MOUFFE sobre la construcción de política de antagonismos basada en el reconocimiento de un exterior constitutivo, es decir, en la formación de identidades políticas adversariales que sólo pueden reconocerse como tal en la medida que se distinguen de un opositor. "[L]a vida política nunca va a poder liberarse de su carácter antagónico, dado que su actividad se circunscribe a la acción pública y a la formación de identidades colectivas. Su objetivo es construir un «nosotros» frente a un «ellos», lo que implica que, en determinadas condiciones, esa relación adopte la forma de una confrontación del tipo amigo/enemigo. Por este motivo, la meta final de la política democrática no es alcanzar un consenso en el que no haya exclusión -lo que equivaldría a crear un «nosotros» sin un «ellos» correspondiente-, sino construir esa distinción nosotros/ellos de un modo que sea compatible con las instituciones democráticas". MOUFFE Chantal, Política y pasiones. El papel de los afectos en la perspectiva agonista, Valparaíso, Editorial Universidad de Valparaíso, 2016.

27 Lo colectivo involucrado en la finalidad de la protesta puede advertirse desde su composición social hasta sus objetivos y demandas involucradas. Es necesario señalar que toda protesta social es un acto colectivo en la medida que permite un espacio en que el grupo movilizado puede reflexionar sobre su realidad y el contexto en que está inmerso, esto puede observarse en formas usuales de movilización como las jornadas de reflexión al interior de establecimientos educacionales o asambleas de estudiantes o trabajadores que deliberan mancomunadamente, propendiendo a la horizontalidad en la reflexión política. Como señala Lorenzo Cadarso, a propósito de la hipótesis que sostiene en el desarrollo de un movimiento social, lo táctico predomina por sobre lo ideológico, existe un proceso que explica “que todo conflicto, su dinámica y la movilización social que implica, provoca una reinterpretación de la realidad social y de las ideas políticas preexistentes en tono contencioso, generando o inventando su propio marco interpretativo de la realidad y su particular autoidentificación ética e ideológica. Al ser el conflicto un proceso dinámico, las percepciones del grupo tienden a evolucionar y, en su caso, a diversificarse según el grado y la forma del compromiso de cada sector con el movimiento", LORENZO, Ibid, 148. 
contra el empleador, la agresión a un transeúnte) no debe convertirse -como suele ocurrir en nuestro derecho- en una excusa para socavar el ejercicio del derecho constitucional principal entonces en juego (la huelga, la protesta)" 28 .

A pesar de las buenas intenciones de este liberalismo progresista, no deja de ser una reflexión que se verifica en abstracto, sin asumir la facticidad de toda protesta. Más allá de la comprensión norteamericana, la protesta no suele ser la mera suma espontánea de individuos; se trata de una acción colectiva cuya orgánica y patrones de movilización dependen, precisamente, de lo colectivo. Como advierten Diani y Della Porta: "Collective action cannot occur in the absence of a "we" characterized by common traits and a specific solidarity. Equally indispensable is the identification of the "other" defined as responsible for the actor's condition and against which the mobilization is called. The construction of identity therefore implies both a positive definition of those participating in a certain group, and a negative identification of those who are not only excluded but actively opposed"29. La correlación de fuerzas de toda protesta permite generar un poder suficiente para alcanzar las metas comunes, lo que no depende de decisiones individuales, sino más bien de decisiones compartidas que configuran la estrategia común. Aquello ha sido relevado mediante la distinción de grupos comunitarios y grupos asociativos en el estudio del conflicto social, en los términos que lo presenta: "los grupos comunitarios se caracterizan por la existencia de lazos de sociabilidad de tipo emotivo y entre ellos, sin descartar la existencia de intereses compartidos, priman como elementos aglutinadores sentimientos tales como las relaciones afectivas, la confianza mutua, etc. El ejemplo más acabado de grupo comunitario sería la familia o, en general, los grupos conformados por relaciones familiares o de dependencia clientelar. Los grupos asociativos son aquellos en los que prima la coincidencia de intereses, bien por compartir determinados referentes ideológicos -un partido político o una religión, por ejemplo- o simples aficiones -los hinchas de un equipo de fútbol, por ejemplo-, bien por pertenecer a un mismo grupo de status o socioprofesional- un sindicato, por ejemplo" 30 .

Así, la propuesta de Gargarella de tratar individualmente la eventual responsabilidad jurídica de cada protestante es propia de autores que estudian el conflicto social desde la elección racional de cada individuo ${ }^{31}$. En esta teoría, la cuestión individual es la unidad básica para analizar el conflicto, ya que lo crucial son los intereses personales de cada sujeto y las decisiones conscientemente asumidas por ellos. Sin embargo, los intereses individuales que puedan motivar a un sujeto a involucrarse en una protesta, son relativizados desde el momento en que una protesta se articula en torno a repertorios de tácticas de acción colectiva, cuya utilidad responde esencialmente a la idea de individuos organizados y no meramente aglutinados ${ }^{32}$.

Separar al manifestante para perseguir una eventual responsabilidad jurídica como propone Gargarella-, supone desconocer que la composición de los grupos

28 GARGARELLA, 2007, Ibid, 56.

29 DIANI y DELLA PORTA. Ibid, 94.

30 LORENZO, Ibid, 128.

31 Para una revisión desde la microsociología del conflicto, puede consultarse: REX John, El conflicto social, Madrid, Siglo XXI de España Editores, 1985.

32 LORENZO, Ibid, 162. 
movilizados a menudo presenta jerarquías internas o los diversos grados de consenso y legitimidad en torno a uno o varios individuos que, por las funciones que cumplen dentro del colectivo movilizado, son fundamentales para el éxito de la manifestación. Por lo tanto, separarlos del resto del colectivo movilizado puede afectar gravemente la efectividad de dicha movilización social, neutralizando su poder para incidir en la autoridad o en la opinión pública. La propuesta jurídica progresista parece tentadora -que podríamos resumir en 'castigar al violento, respaldar al pacífico'-, pero acarrea una consecuencia política que no ha sido suficientemente considerada. Del mismo modo que los dirigentes sindicales gozan de un fuero que permite balancear las relaciones de poder del empleador en su rol de representación de los trabajadores, en la protesta social también se presentan tanto jerarquías internas y responsabilidades en relación al colectivo movilizado, como una relación de poder extraordinariamente favorable a la autoridad contra la cual se protesta o que podría estar en posición de tomar represalias contra los manifestantes. Desde esta perspectiva, la idea de tratar a todos los protestantes separadamente no sólo implica una comprensión desmedidamente individual sobre los movimientos sociales, sino una debilidad del derecho para relacionarse con el fenómeno de la protesta social.

\section{El derecho a protestar: ¿individual o colectivo?}

Esta debilidad puede explicarse a partir de los propios elementos del constitucionalismo y del discurso de los derechos. La concepción de la protesta como un derecho parece estar construida sobre dos niveles: las razones para protestar, por un lado, y el concepto jurídico del acto de protesta, por el otro. En el primer nivel, Gargarella parece aludir a consideraciones que ponen énfasis en lo colectivo, tales como: la situación de injusticia estructural que padecen ciertos grupos, su incomunicación institucional en la toma de decisiones y los escasos canales de difusión de información con que cuentan. En suma, se habla de razones para protestar sobre la idea de una necesidad compartida por un conjunto de individuos para solucionar sus padecimientos, solución que no ha sido posible obtener mediante los canales de participación política formal. En esta línea, se afirma que "lo que importa, en definitiva, es que los grupos más desaventajados puedan tornar visibles sus demandas, de forma de asegurar la satisfacción de sus necesidades básicas" 33 .

En cambio, el segundo nivel reafirma la dimensión individual para procesar jurídicamente el acto de protesta, al identificar la libertad de expresión individual de la primera enmienda como el núcleo del derecho. Estos dos niveles -colectivo e individualtienden a cruzarse en una vinculación que no parece encajar del todo, donde a veces la colectividad es leída como la mera agrupación de individuos para los fines de la protesta, o bien, lo colectivo es el parangón para juzgar la neutralidad de las regulaciones de la protesta como, por ejemplo, que las regulaciones de la protesta deben ser aplicadas uniformemente a todos los grupos.

Así, la cuestión individual/colectiva en el núcleo del derecho a la protesta genera una confusión que opera en la idea misma de un derecho subjetivo a protestar. En todo

33 GARGARELLA, 2015, Ibid, 35. 
derecho subjetivo encontramos cuestiones ético-filosóficas y jurídico-dogmáticas ${ }^{34}$. Mientras las primeras han permitido argumentar en favor de las razones colectivas para un derecho a la protesta, las segundas han servido para delimitar jurisprudencialmente el acto mismo de la protesta, con conceptos y discursos propios de la titularidad y ejercicio individual del derecho subjetivo. Lo que está por verse, entonces, es si puede avanzarse en el diseño de un derecho a protestar ejercido asociativa y colectivamente y cómo ello implica modificar la doctrina de la libertad expresiva individual, dada su insuficiencia para significar una actividad que reclama ser más que el mero aglutinamiento de individuos.

La teoría constitucional se ha desarrollado durante largos años sobre la premisa de que los derechos fundamentales pueden ser comprendidos a partir de la estructura de un derecho subjetivo. Bajo esta categoría, un sujeto está facultado jurídicamente para requerir de otro una determinada conducta, que constituiría el contenido del derecho. Así, la misma estructura lógica podría seguirse ante la provisión de un derecho constitucional como podría ser el acceso a la información pública: el sujeto $A$, el ciudadano, puede requerir del sujeto $B$, el Estado, que se comporte en el modo $C$, entregando los antecedentes e informaciones que obren en su poder cuando sean requeridos. Sin embargo, esta estructura normativa plantea una dificultad mayor respecto de la protesta: si la sociología política ha mostrado que las protestas tienen particularidades que las hacen únicas y totalmente distinguibles entre sí35, ¿cómo podrían ser encapsuladas en una única forma jurídica -el derecho subjetivo- para operar frente al Derecho? ¿Quién sería el titular del derecho a la protesta? ¿Quién su destinatario? ¿Cuál es el contenido de este derecho? Nótese que, si se acepta la conceptualización de la protesta como libertad de expresión, estas interrogantes pueden ser rápidamente contestadas: el ciudadano sería el titular, el destinatario sería el Estado impedido de establecer restricciones arbitrarias y el contenido se identificaría con la descripción formal de la libertad de expresión individual hecha por la doctrina. No es necesario un gran esfuerzo teórico para encasillar la protesta social dentro del aparato conceptual del derecho individual; pero creemos que esa definición no es funcional a los intereses de quienes protestan ni a las formas de acción que se alejan de los modos de ejercicio de los derechos individuales.

Sabemos que las protestas no se ejercen siempre por los mismos sujetos, no se dirigen siempre contra el mismo destinatario y no persiguen siempre la misma finalidad. Se trata de una actividad que difícilmente puede concebirse dentro de la comprensión de la libertad de expresión que el liberalismo jurídico ha propuesto, pues se trataría un derecho subjetivo ejercido de forma colectiva. El desafío analítico y teórico consiste en acercar la idea de un derecho subjetivo a los términos en que los estudios especializados han caracterizado a la protesta: como una actividad política que se ejerce

\footnotetext{
34 CRUZ PARCERO, Juan Antonio, El lenguaje de los derechos. Ensayo para una teoría estructural de los derechos, Madrid, Editorial Trotta, 2007.

35 Para una revisión acuciosa sobre las características de los diversos tipos de protesta social, puede consultarse: TILLY Charles, Los movimientos sociales, 1768-2008. Desde sus orígenes a Facebook, (Traducción: ESTEVE Ferrán), Barcelona, Editorial Crítica, 2010. Sobre consideraciones metodológicas en la sociología para estudio del conflicto y de la protesta social, véase: SCRIBANO, op. cit.
} 
mancomunadamente por un conjunto de individuos, siguiendo repertorios estratégicos de movilización política ${ }^{36}$.

Los derechos subjetivos son ejercidos individualmente, de manera excluyente. Así "para la gran mayoría de los teóricos liberales, el único titular de derechos es el individuo $\mathrm{y}$, por tanto, todo tipo de derechos es individual. El problema que se presenta si se adopta esta posición es el explicar entonces la adscripción de derechos a entidades como las corporaciones, universidades, empresas, sindicatos y todo tipo de asociaciones incluido el Estado. La respuesta que han dado los teóricos del Derecho consiste en recurrir a una serie de teorías que distinguen entre personas físicas y personas jurídicas o morales. En estas teorías, los grupos, sociedades, comunidades, etc., son vistos como una persona individual" 37 .

En el caso de la protesta parece difícil imaginar que un colectivo movilizado pueda asumir la forma de una persona ficticia de derecho, puesto que la emergencia de estos grupos no sigue los patrones propios de la constitución de las personas jurídicas, las que se constituyen y registran frente a la autoridad en virtud de la ley. Por el contrario, en el caso de los movimientos sociales, "no se trata de actores que pretendan tener una presencia permanente en el sistema, ni participar directamente en el proceso electoral o en administrar por su cuenta el poder político" 38 . El derecho, como parámetro para identificar o medir lo colectivo, parece ser ante todo insuficiente, inclusive, como nos recuerda Tarrow, la dimensión colectiva de los movimientos sociales debe ser leída en clave histórica, ayudada por la sociología, la ciencia política y la antropología, para así identificar las características básicas de los movimientos sociales: "In particular, we will see that bringing people together in sustained interaction with opponents requires a social solution - aggregating people with different demands and identities and in different locations in concerted campaigns of collective action. This involves, first, mounting collective challenges, second, drawing on social networks, common purposes, and cultural frameworks, and third, building solidarity through connective structures and collective identities to sustain collective action. These are the basic properties of social movements" 39 .

Es tal el grado de abstracción verificada en la reunión del colectivo, que autores como Judith Butler han planteado que la reunión de individuos en protesta como una actividad performativa que simboliza la idea de un cuerpo político escindido de las estructuras políticas formales, que se expresa a semejanza de la propia sociedad política soberana que valida las instituciones y, desde luego, al Derecho: "se desprende de tal noción que los cuerpos reunidos para afirmar su existencia plural están ya autodesignándose y ejercitando la soberanía popular, prestando o retirando su apoyo, declarando su independencia de los regímenes cuya legitimidad depende de ello. El

\footnotetext{
36 LORENZO, Ibid, 159-178.

37 CRUZ PARCERO, Ibid, 110.

38 MUJICA Pedro, Poder en disputa. Partidos politicos, grupos de interés y movimientos sociales, Santiago, Ediciones Universidad Alberto Hurtado, 2014.

39 TARROW Sidney, Power in movement. Social movements and contentious politics, New York, Cambridge University Press, 2011.
} 
performativo se encuentra así fuera del poder electoral al mismo tiempo que funciona como su legitimación" 40 .

La aporía de aquella dimensión colectiva que es inherente a la protesta también puede pensarse a propósito del objeto del Derecho, cuando los bienes jurídicos involucrados puedan ser concebidos en clave colectiva. Al respecto Cruz Parcero, tomando la reflexión de Joshep Raz, entrega algunas pautas: "un derecho colectivo existe cuando se dan las siguientes tres condiciones. Primera, existe porque un aspecto del interés de los seres humanos justifica sostener que alguna(s) persona(s) esté(n) sujeta(s) a un deber. Segunda, los intereses en cuestión son los intereses de los individuos en tanto miembros de un grupo en un bien público y el derecho es un derecho a ese bien público porque sirve a sus intereses como miembros del grupo. Tercera, el interés de ningún miembro del grupo en el bien público es suficiente por sí mismo para justificar mantener que otra persona esté sujeta a un deber" 41 .

Sin embargo, creemos que es muy difícil aplicar la propuesta de Raz al derecho a protestar, toda vez que las cuestiones de conflictividad y las formas contenciosas de movilización no han sido aceptadas por el discurso constitucional como formas legítimas del ejercicio del derecho a la protesta. Sumado a lo anterior, la idea del interés de un individuo en un grupo respecto de un bien público, tal como es descrito, es una cuestión variable en la protesta social, toda vez que ella puede confluir una diversidad de grupos e intereses que hagan difícil su unificación. Además, la noción de bien público es un concepto aún más difícil pues, siguiendo los estudios especializados ${ }^{42}$, la protesta podría perseguir los mismos bienes que la política institucional: la profundización democrática, la satisfacción de una necesidad social urgente o el intento de balancear un poder desbordado. En suma, la protesta social, en tanto actividad política de grupos sociales transitorios, se presenta como un ejercicio colectivo muy distinto al que realiza, por ejemplo, un grupo étnico que reclama de un Estado el reconocimiento oficial de sus símbolos identitarios o la garantía de intervenir, mediante un derecho colectivo a la consulta indígena, en políticas públicas que pudieran afectarles.

Podría argumentarse que la construcción jurisprudencial de la protesta social ha tenido a la vista que la expresión verificada en los foros públicos podría ser ese bien público colectivo al que Raz hace referencia ${ }^{43}$. Pero su insuficiencia queda en evidencia ante la diversidad de fenómenos de protesta y las pretensiones de los colectivos movilizados en cada una de ellas, donde el uso del espacio público no es una finalidad, sino una necesidad para la visibilización efectiva del acto de protesta. En último término, es fundamental reconocer que los modos y fines de la protesta social pretenden la impugnación a la autoridad como parte de la lucha reivindicativa 44 , lo que escapa a las consideraciones

40 BUTLER Judith, “«Nosotros, el pueblo». Apuntes sobre la libertad de reunión”, en ¿Qué es un pueblo?, Santiago, Editorial LOM, 2014, 41-59.

41 CRUZ PARCERO, Ibid, 114.

42 CRUZ PARCERO, Ibid, 145-157.

43 RAZ Joseph, The Morality of Freedom, Oxford, Oxford University Press, 1988.

${ }_{44}$ Aquello no sólo puede verse sólo mediante las prácticas disruptivas, sino como la característica constitutiva de ciertas protestas sociales que se levantan, precisamente, buscando impugnar a los gobernantes, tratando generar climas y situaciones políticas que tiendan a debilitar a la autoridad frente a la sociedad. Ejemplos de 
propias de la teoría del derecho sobre la identidad y límites de un objeto en un derecho subjetivo.

\section{Límites epistémicos de la libertad de expresión frente a la protesta social}

Si bien es patente la gran diversidad de formas y expresiones de protesta social a lo largo de la historia, puede reconocerse que un denominador común en ellas es la idea de la desinstitucionalización de sus formas, es decir, puede reconocerse como protesta en tanto actúa con libertad -e, incluso, con violencia ${ }^{45}$ - respecto de la institucionalidad estatal y jurídica. Esto ha sido así puesto que las formas institucionales a menudo implican restricciones y condicionan resultados, todo ello, radicalmente opuesto a la propia elasticidad y diversidad de movilizaciones que caracterizan a la protesta. Por esto, cabe preguntarse si la misma herramienta que ha servido para mostrar la cara más tolerante del derecho frente a la protesta social (la doctrina del tiempo, lugar y modo) no es también la más útil para su neutralización vía juridificación. Se advierten, entonces, dos caras de una misma moneda: el derecho a protestar como parte del andamiaje constitucional, por un lado, y la protesta juridificada y neutralizada por este mismo andamiaje, por el otro.

Esta contradicción presenta un inconveniente difícil de resolver, al evidenciar las justificaciones políticas más profundas de la protesta social: ¿qué es lo que se hace cuando se protesta? ¿puede la sociedad sentirse políticamente motivada de la misma forma cuando protesta que cuando se participa de un procedimiento administrativo? La doctrina constitucional más reciente invita a pensar el derecho a la protesta tanto desde la participación ciudadana, en una comprensión democrática amplia, como desde el responsiveness de la autoridad ${ }^{46}$. Sin embargo, la protesta social reclama ser algo distinto, que no se desenvuelve mediante plazos, requisitos y legitimaciones activas; ella encarna, en cierta forma, lo que Horacio González denominaba la resistencia al derecho. La protesta es protesta, precisamente porque se resiste a las categorías jurídicas que higienizan lo político y que fijan fronteras entre lo aceptable y lo inaceptable. La emergencia de un afán regulador de la protesta, entonces, puede explicarse de la siguiente forma: "puede invocarse el derecho como la raíz misma de la civilización si se entiende ésta como la conjura del acto sin nombre. El derecho pone los nombres cabales; no los nombres que surgen de la dubitación de los hablantes cotidianos (...) En verdad, la trama del derecho siempre está a la espera de un hecho que puede ser atraído a modo de caso singular,

protesta de este tipo son variados, entre ellos: las Jornadas de Protesta Nacional en contra la dictadura de Augusto Pinochet, entre 1982 a 1986, en Chile; el Cacerolazo de 2001, con el lema “iQué se vayan todos!", en Argentina; la protesta nacional boliviana del año 2012, en contra del gobierno de Evo Morales; las protestas del Movimiento de los Indignados del año 2011, en Madrid.

45 Sobre las causas de las protestas violentas en Chile, MONTONI RÍOS Ángelo, “Movimientos sociales y violencias colectivas: factores explicativos desde la frustración relativa", Actuel Marx (No 13, 2012$), 49$ ss.

46 En este punto, Lovera sostiene que "en las avenidas políticas existe la posibilidad de considerar las propuestas de la ciudadanía (una y otra vez) 'desde cero', lo que es crucial para reclamos de grupos marginados que quieren llamar la atención sobre sus demandas desoídas”, LOVERA Domingo, “¿Tres son multitud? Constitucionalismo Popular, Cortes y Protesta" [En línea]. [fecha de consulta: 9 de febrero de 2018]. [Disponible en: https://www.academia.edu/7933336/_Tres_son_Multitud_Constitucionalismo_popular_cortes_y_protesta] 
subsumido con estricta inmediatez. Esta inmediatez revela que todo acto existencial ordinario goza de una libertad rústica relativa o inconsciente hasta que pueda entrar en la malla del derecho" 47 .

González reconoce que la emergencia de categorías jurídicas para nombrar los actos humanos, permite al sistema jurídico darles vida a estos fenómenos, no en el sentido de nutrirlos u oxigenarlos, sino en el sentido de afirmar que antes del derecho el acto sólo aparece como incierto o nebuloso. Así, se afirma que una institución ha nacido a la vida del derecho cuando un fenómeno social adquiere la importancia suficiente para ser nombrado y regulado por el derecho. Algo similar ocurre con la protesta social, antes de las reflexiones que proponen reconocerla como un derecho, ella era vista como un acto nebuloso, del que a veces se sospechaba hasta insurrección. Hoy, en cambio, la protesta se propone como un fenómeno no sólo compatible con el constitucionalismo, sino que compartiendo sus principios políticos elementales. Este acercamiento al constitucionalismo, producido por la reflexión que la nombra como derecho, tiene una consecuencia inevitable: la restricción de sus posibilidades y el condicionamiento de sus resultados según el criterio del tiempo, lugar y modo, como un criterio jurídico de regulación de un derecho fundamental. Aquello invita a pensar, entonces, si acaso la protesta en tanto acción no institucional, junto a las finalidades políticas específicas que persigue, pretende resistirse a la categorización jurídica de los actos políticos tan propia de nuestras democracias liberales contemporáneas; aquello que González propone como resistir al derecho: "cuando surge la necesidad de resistir a esa red de palabras normalizadas, aun admitiendo que permiten la utopía del vivir común, encontramos el sentimiento de resistencia al derecho. La verdadera opresión" 48 .

Todo aquello, sumado a la adopción de patrones disruptivos por los movimientos sociales, mediante los cuales intencionadamente se rechaza el cauce legal, permite inferir que la resistencia a la juridificación no sólo es algo aspirado por los grupos en conflicto, sino totalmente necesario para los fines de la movilización.

Es un hecho notorio que cuando se habla de protesta también se habla de libertad de expresión; se trata, en cierta medida, de una vinculación adecuada. Sería tremendamente ingenuo y argumentativamente deficiente decir que protestar no implica una manifestación de la libertad de expresión. En efecto, toda protesta social se articula en los modos expresivos más diversos, desde formas tan típicas como la exclamación de consignas políticas hasta algunas más contemporáneas, como las representaciones performativas. Es notoria la presencia del ejercicio expresivo en una movilización, de modo que no cabe posibilidad de omitir esto ni menos disminuir su importancia. Sin embargo, durante los últimos años, la libertad de expresión ha sido la explicación exclusiva y excluyente a la hora de justificar el derecho a la protesta, generando cierta uniformidad en la doctrina, al punto que la única cuestión relevante sea el rol de la libertad de expresión en los sistemas democráticos y su eventual potencia como una actividad política, dejando fuera otras reflexiones igual de importantes. Gargarella ha sido

47 GONZÁLEZ Horacio, "La resistencia al derecho" en El derecho a resistir el derecho, Buenos Aires, Miño y Dávila Editores, 2015, 117-120.

48 GONZÁLEZ, Ibid, 120. 
consciente de ello, cuando reconoce que "lo central se encuentra en otro lugar. Esto es: cómo devolverle a quienes protestan la dignidad y derechos que pierden, demasiado habitualmente, en manos de quienes debieran aseguran la satisfacción de sus intereses fundamentales" 49 .

A pesar de esta consciencia, es posible apreciar una cierta anomalía teórica en las restricciones de tiempo, lugar y modo, propias de la comprensión de la libertad de expresión en Norteamérica. Si bien la doctrina del prior restraint se encuentra ampliamente difundida (en el sentido de no establecer restricciones expresivas a priori, y que una persona sólo debe ser responsable por manifestaciones expresivas pasadas ${ }^{50}$ ), parece incompatible con la doctrina del tiempo, lugar y modo. En efecto, al tiempo que afirma que la protesta social es una derivación de la libertad de expresión y que se encuentra protegida por la garantía de la primera enmienda, se le reconocen ciertas facultades a la autoridad, que le permiten controlar su desarrollo, al establecer condiciones y modos ideales para que se desenvuelva. Ahora bien, sin perjuicio que estas facultades de la administración están sujetas a un strict scrutiny, no deja de ser paradójico que ellas se asemejen a un tipo de regulación estatal de censura previa para la protesta $y$, aunque se ofrezca la posibilidad de derrotar judicialmente estas restricciones, lo cierto es que los efectos del control estatal ya se han impuesto por sobre la protesta.

Lo anterior genera una paradoja: ¿por qué el compromiso con la libertad de expresión, tan fuerte en otros ámbitos tales como la libertad de prensa, encuentra excepciones para el ejercicio de la protesta? Aquello parece interrogar nuevamente sobre cómo la relación protesta/expresión es procesada por el constitucionalismo. A pesar de que es evidente que toda protesta incluye actos expresivos, el constitucionalismo ha hecho grandes esfuerzos para concebir la protesta desde el marco teórico de los derechos individuales. Al hacerlo, ha terminado por totalizar el campo de significación apto para pensar el conflicto social, rindiéndose a una categoría jurídica propia de otros contextos y que persigue otros objetivos, subsumiendo la acción colectiva en formas tradicionales que ya tienen un significado prefigurado. Si se piensa detenidamente, a pesar del esfuerzo teórico del constitucionalismo, lo cierto es que el Estado se ve obligado a no tratar a la protesta como trata a la libertad de expresión, pues las cuestiones sobre la violencia y conflicto social tienden a desbordar las categorías tradicionales de la libertad de expresión individual.

En este sentido, la aproximación del constitucionalismo hacia la protesta social desde la libertad de expresión sirve, a lo mucho, para una comprensión adjetiva de ella, donde la expresión es un mero vehículo para la protesta. Sin embargo, lo realmente sustantivo está en lo que el derecho constitucional no considera, es decir, en el rol de la protesta como acto de acción política directa. Es por eso que una protesta modelada por la autoridad tiene poco o nada de sentido, pues la transforma en un acto meramente testimonial -en el mismo modo que es testimonial la desobediencia civil sujeta a la

49 GARGARELLA Roberto, "Prólogo: Derecho a la protesta: pensarlo todo de nuevo", en Criminalización de la protesta. La respuesta del Estado frente a los reclamos ciudadanos, Buenos Aires, Editorial Ad Hoc, 2015a, 11-18.

50 TOLLER Fernando, El formalismo en la libertad de expresión. Crítica de la distinción absoluta entre restricciones previas y responsabilidades ulteriores, Madrid, Marcial Pons, 2011. 
condición de ser pública y pacífica- pues aquello sirve para que el Estado pueda anticiparse a la emergencia de cualquier acción radicalizada ${ }^{51}$.

\section{Hegemonía constitucional frente a la acción política de protesta}

No es extraño que un fenómeno tan alejado del consenso constitucional como la protesta social, sea rápidamente cooptado por el paradigma constitucional y sus operadores, tiñéndolo con los rasgos propios de una actuación juridificada que sólo puede ser procesada en el contexto de la protección constitucional. La cultura jurídica y política norteamericana tiende a exaltar el valor de su sistema constitucional como el arreglo idóneo que permite solucionar las fricciones dentro de la sociedad. En efecto, existe un intenso debate en el constitucionalismo sobre las formas más correctas de interpretar la constitución ${ }^{52}$, siempre bajo la premisa de que una Constitución con altos grados de aceptación en la sociedad, puede actuar como un instrumento de cohesión social. Este fenómeno también se ha presentado en otras latitudes con el nombre de patriotismo constitucional53, pero en Norteamérica presenta algunas características que Duncan Kennedy expone con ironía y escepticismo:

En tanto creamos en el pueblo constitucional y en que el proceso interpretativo se ha hecho correcta o incorrectamente, de buena fe o a través de manipulación consciente, podríamos comprender nuestra historia constitucional en el modo del patriotismo y de la moral.

Patriotismo. Nuestra Constitución expresa nuestras cualidades particulares como pueblo, y su interpretación e implementación frente a normas en conflicto sostiene esas cualidades. La interpretación constitucional es por lo tanto un modo de autodeterminación nacional. Podemos diferenciar dos maneras en que nuestra identidad nacional nos distingue de otras naciones: 1) El constitucionalismo mismo es especialmente norteamericano -otros no se abocan a nuestra forma particular de autodeterminación a través de la interpretación, y prefieren en cambio modalidades violentas o meramente políticas-. 2) La particular constelación de derechos y libertades civiles y personales de que gozamos derivan de nuestro particular esquema constitucional adaptado a través del tiempo a nuestros valores cambiantes, $\mathrm{Si}$ hemos sido, somos y, si Dios quiere, siempre seremos el pueblo más libre del mundo, lo hemos logrado adoptando una Constitución que garantiza la libertad y luego interpretándola e implementándola a medida que los casos iban surgiendo.

Moral. Nuestra Constitución encarna los compromisos morales de nuestra subjetividad más elevada e idealista. La política es la Tierra corrompida en relación con el Cielo de

51CELIKATES Robin, "Rethinking civil disobedience as a practice of social contestation. Beyond the liberal paradigm", en Constellations (Vol. 23, No 1, 2016), 37-45.

52 Los diversos modos de interpretar la constitución en los Estados Unidos han sido un tópico de álgido debate entre los que destacan posturas como el originalismo de Thomas Bork y Antonin Scalia; la constitución viva de David Strauss; el constitucionalismo democrático de Robert Post y Reva Siegel, entre otros.

53 El término fue acuñado por Jürgen Habermas para referirse a la construcción de identidades nacionales basadas en el consenso sobre valores políticos compartidos y establecidos en un texto constitucional. El patriotismo constitucional fue una respuesta para la reconstrucción de las naciones europeas fracturadas por los efectos de la segunda guerra mundial. 
las aspiraciones constitucionales. La verdadera interpretación constitucional es por lo tanto una especie de intervención angélica en los asuntos de la vida cotidiana. Nos sometemos a ella de manera real y coercitiva para alcanzar una virtud que no tendríamos la fuerza, la imaginación o los recursos para alcanzar si nos abandonáramos a nuestras prácticas políticas normales. La falsa interpretación puede estar equivocada, en cuyo caso pierde sus beneficios, o puede ser conscientemente manipuladora, en cuyo caso lo profano invade la esfera de lo divino, corrompiéndola. La historia constitucional es la historia de la ampliación gradual del influjo celestial, dado que la Corte ha protegido pero también ampliado los derechos civiles y humanos básicos frente a las agresiones y resistencias de la política ${ }^{54}$.

Kennedy parece hacer referencia a la idea anquilosada en el inconsciente colectivo de los Estados Unidos que su Constitución, lejos de ser una victoria política sectorial, como ocurre en todo el mundo, es un espacio de conflagración de las más altas virtudes políticas, y que sólo a través de esta, es posible escapar las prácticas políticas normales. Se hace referencia, entonces, a un espacio sano y justo que, de ser posible, debiera colmar e influir en todos los espacios de la convivencia social.

Esta construcción jurisprudencial del derecho a protestar presenta varias interrogantes sobre el alcance de los discursos jurídicos en tanto discursos de verdad55, así como su rol en la reproducción de determinado orden político y social. En este sentido, no basta con plantear el problema desde la competencia de los jueces para crear derecho e impugnar desde allí el contenido que se ha realizado por los jueces del derecho a protestar; por el contrario, creemos que es necesario atender a los modos en que este discurso jurídico se construye y es luego presentado como la verdad razonable y objetiva.

En primer lugar, cabe resaltar que el contexto de la doctrina de la protesta como derecho nos habla de la enorme influencia de los discursos jurídicos, que Sandoval Cervantes denomina como teoría jurídica tradicional dominante y que identifica en pensadores como Robert Alexy, Ronald Dworkin, Luigi Ferrajoli y otros integrantes de la corriente de los neoconstitucionalismos. Esta corriente del pensamiento jurídico ha puesto énfasis en pensar la producción jurisdiccional del Derecho fuera de los mecanismos tradicionales del poder, apoyada en una especie de moral humana universal y natural 56 , en

\footnotetext{
54 KENNEDY Duncan, Izquierda y derecho. Ensayos de teoría jurídica crítica, Buenos Aires, Siglo XXI Editores, 2010.

55 BRION y HARCOURT describen la noción foucaultiana de verdad del siguiente modo: “Al hablar de régimen de verdad, Foucault entiende, por analogía, "el conjunto de los procederes y las instituciones que comprometen y constriñen a los individuos a realizar, en ciertas condiciones y con ciertos efectos, actos bien definidos de verdad". Actos que son otras tantas obligaciones de verdad y que constituyen "la parte que corresponde a un sujeto" en una aleturgia. La noción de régimen de saber se define por la articulación de un régimen de verdad con régimen político-jurídico. Establece, entre lo epistemológico y lo político, una relación en la cual el sujeto es nodal: sujeto en el "doble sentido de la palabra [...], sujeto en una relación de poder, sujeto en una manifestación de verdad" BRION Fabienne y HARCOURT Bernard, "Situación del curso", en Michel Foucault, Obrar mal, decir la verdad. La función de la confesión en la justicia. Curso de Lovaina, Buenos Aires, Siglo XXI Editores, 2014, 281-340.

56 SANDOVAL Daniel, "El Estado democrático de derecho en términos de dominación: justicia constitucional y violencia simbólica", en Alegatos, (N83, 2013), 31-54.
} 
que el discurso de los derechos humanos se ofrece no sólo como una parte constitutiva del sistema jurídico, sino además como una garantía última de su legitimidad 57 .

Este fenómeno ha producido que los jueces se alcen como las voces autorizadas no sólo para decir el derecho, sino para formular eventuales correcciones a los discursos de los ciudadanos, de un modo que permita acercarlos al lenguaje jurídico, produciendo relatos jurídicos oficiales y definitivos. Para hacer esto posible, la formación discursiva del derecho opera bajo la división de sujetos especializados y no especializados en el lenguaje jurídico. La racionalidad jurídica es presentada como el resultado de una repartición específica de roles discursivos y de capacidad de producción de enunciados válidos. Esta repartición en la producción discursiva del Derecho, tratándose de los derechos humanos, como el caso de la libertad de expresión en la protesta, sitúa a los jueces como intérpretes últimos del significado libertad de expresar involucrado en un eventual derecho a protestar. Aquello opera mediante dos elementos: i. la función hermenéutica del juez en la producción del discurso del derecho válido y ii. la conducta de relato a la que se deben someter los individuos no funcionarios para participar en la producción de dicho discurso ${ }^{58}$.

El primer concepto de función hermenéutica indica cómo el juez que conoce de un caso a partir de una alocución de un sujeto no especializado debe transformar ese discurso en uno que sea expresión de racionalidad jurídica, traduciendo el discurso a derecho, mediante "métodos interpretativos y herramientas argumentativas no disponibles para sujetos no especializados. A partir de lo cual transforma el discurso inicial en un discurso jurídico verdadero y válido" 59 .

En sentido, puede observarse cómo en los casos conocidos por la Suprema Corte, mediante los cuales se ha cimentado la doctrina de las regulaciones neutrales de la protesta, se produce una operación en que las eventuales motivaciones conflictuales en la protesta, así como sus impugnaciones a un orden político que se estima injusto, son higienizadas y escritas en un lenguaje natural del constitucionalismo, el lenguaje de los derechos. Dadas las formas en que se construyen los discursos jurídicos de verdad, la alocución de los sujetos protestantes, en tanto sujetos jurídicos no especializados, terminará traducida, casi exclusivamente, en el discurso de la libertad de expresión. Así, "el discurso inicial del individuo no especializado constituye un discurso desarticulado que contiene cierto grado de verdad, pero de manera tan oscura que ésta realmente es sacada en todo su esplendor por el trabajo hermenéutico del juez. De manera que es el juez el poseedor y el productor del discurso del derecho válido y verdadero, mientras que el sujeto no especializado constituye solamente un objeto de tal discurso, y no su productor. De esta manera es la determinación de quien es el sujeto especializado, así como de las técnicas argumentativas a las que sólo este tiene acceso, lo que hace posible producir el

\footnotetext{
57 Para una revisión detallada de este tema puede consultarse: FERRAJOLI Luigi, Garantismo. Una discusión sobre derecho y democracia, Madrid, Editorial Trotta, 2009.

58 SANDOVAL, Ibid, 35-38.

59 SANDOVAL, Ibid, 39.
} 
discurso del derecho válido: una completa asimetría en la producción de la verdad característica del discurso moderno" 60.

Esta especial ubicación del juez en el reparto de lo sensible ${ }^{1}$ le permite construir discursos jurídicos válidos y verdaderos. Que protestar sea entendido, preferentemente, como el ejercicio de una libertad de expresión es un reflejo de cómo se construye un discurso de verdad y de la posición institucional que habilita al juez para fijar los alcances a esta premisa, como la doctrina del tiempo, lugar y modo, que viene a complementar la verdad judicial de la protesta sujeta a la primera enmienda.

El segundo elemento, relativo a la conducta de relatos a que se deben someter los individuos no especializados, se refiere al acatamiento discursivo de los sujetos ordinarios cuando presentan sus causas ante la judicatura. En efecto, ellos buscan presentar sus problemas expresados en clave jurídica o, dicho de otro modo, estructuran su discurso en términos de los parámetros y reglas establecidos por el derecho contemporáneo ${ }^{62}$. Lo que deviene en una reducción estatal de la expresión jurídica de las necesidades reales, o bien, en la monopolización por parte del Estado de la producción del discurso de derecho válido, de tal manera que toda satisfacción de las necesidades reales a través del derecho tiene que pasar por su producción estatal 63 .

En este modo es esperable que el lenguaje no especializado de la protesta sea acercado al derecho cuando es llevado a presencia judicial. Las acciones políticas de movilización colectiva son pasadas por el cedazo de los derechos humanos, lo que permite afirmar, como una verdad judicial, que quien protesta lo hace ejerciendo su libertad de expresión, aunque las diversas motivaciones de la protesta sean, muchas veces, más profundas que la mera aspiración expresiva. Así, la verdad judicial termina por institucionalizar las formas políticas de la protesta, al concebirla desde los contornos propios de la libertad de expresión; al hacerlo, le opone las limitaciones, condiciones y requisitos tradicionales de la libertad de expresión, mediante una operación hermenéutica de equivalencia entre protestar y expresar. Es esperable, entonces, que, aunque se diseñen regulaciones específicas para la protesta, éstas se presenten como limitaciones propias de la libertad de expresión, puesto que previamente la verdad judicial lo ha establecido así, al contener la protesta social dentro de los límites institucionales del derecho expresivo. Al respecto, puede verse la situación acaecida en el año 2014 en el caso Llaguel Figueroa y otros con Ilustre Municipalidad de Santiago, en el cual la Corte de Apelaciones de Santiago resolvió un conflicto suscitado entre la Municipalidad de Santiago y un grupo de apoderados del Instituto Nacional, quienes interpusieron una acción de protección con el objeto de impugnar un protocolo de movilización acordado entre un grupo de estudiantes

60 SANDOVAL, Idem.

61 RANCIÈRE Jacques, El reparto de lo sensible, Santiago, Lom, 2009: “Llamo reparto de lo sensible a ese sistema de evidencias sensibles que al mismo tiempo hace visible la existencia común y los recortes que allí definen los lugares y las partes respectivas. Un reparto de lo sensible fija entonces, al mismo tiempo, un común repartido y partes exclusivas. Esta repartición de partes y lugares se funda en un reparto de espacios, de tiempos y de formas de actividad que determina la manera misma en que un común se ofrece a la participación y donde los unos y los otros tienen parte en ese reparto".

62 SANDOVAL, Idem.

63 SANDOVAL, Ibid, 40. 
movilizados y la autoridad de la comuna de Santiago, cuyo objeto era fijar reglas y criterios para la protesta estudiantil, en lo relativo al desarrollo de paros y tomas como forma de protesta. La Corte de Santiago acogió el recurso, razonando sobre los límites de la libertad de expresión: “En un Estado de Derecho como el que rige en nuestro país la libertad de expresión está garantizada, pero como todo derecho tiene límites, resultando obvio que en uso de ella no se puede imponer medidas de fuerza sino que debe canalizarse por otros medios en ejercicio de esa y otras garantías que el orden institucional permite; así en ejercicio de la libertad de reunión los estudiantes pueden organizar marchas y jornadas de reflexión, en uso del derecho de opinión hacer declaraciones públicas, en ejercicio del derecho de petición formular demandas estudiantiles a la autoridad, etc., pero nunca recurrir a actos de fuerza que no pueden tener lugar en una sociedad democrática que se precie de tal" 64.

Esto no es más que el resultado de una operación propia de la retórica y de las relaciones de poder que se verifican en ella, considerando que "la argumentación está marcada por la asimetría de los participantes, aun cuando sólo sea por la distribución desigual de recursos discursivos tales como las habilidades retóricas o la capacidad cultural. Éstas refuerzan la posición de quienes pueden dominarlas y revelan que la deliberación no depende sólo de la persuasión racional, pues la fuerza y el poder también intervienen en la comunicación entre las partes. Laclau va aún más allá cuando señala que la propia persuasión incluye un elemento de violencia. Está presente, dice, cuando tratamos de convencer a alguien de que cambie sus opiniones por medios puramente argumentativos, pues ello implica la supresión de las opiniones que esa persona tenía inicialmente" 65 .

Lo dicho hasta ahora sugiere pensar al discurso jurídico no sólo como el desarrollo de técnica, sino también como un ejercicio que intenta colmar un campo significativo sobre conceptos de relevancia social y política. Slavoj Ẑiẑek expresaba que "la lucha por la hegemonía ideológico-política es siempre una lucha por la apropiación de aquellos conceptos que son vividos «espontáneamente» como «apolíticos»" $66 \mathrm{y}$, en cierta medida, bien podría decirse que la hegemonía del constitucionalismo frente a la acción política de protesta ${ }^{67}$ opera del mismo modo, entregando nombres cabales y apropiando conceptos

${ }^{64}$ Llaguel Figueroa Carlos y otros con Ilustre Municipalidad de Santiago (2014): Sentencia de la Corte de Apelaciones de Santiago, Recurso de Protección, Rol N³9.022- 2014.

65 ARDITI Benjamín, La política en los bordes del liberalismo. Diferencia, populismo, revolución, empancipación, Barcelona, Editorial Gedisa, 2011.

66 ŽIŽEK Slavoj, En defensa de la intolerancia, Madrid, Ediciones Sequitur, 2008.

67 La elaboración de un concepto de constitucionalismo hegemónico constituye un esfuerzo que desborda los límites de este trabajo y que requiere de precisiones mayores. Sin embargo, en lo relativo al encuentro entre constitucionalismo y protesta, entendemos que en el derecho se ha ido asentando un cauce discursivo que supone totalizar el campo de posibilidades conceptuales para la protesta, a partir de las categorías del constitucionalismo norteamericano. Aquello implica no sólo oponer dispositivos propios del derecho constitucional a la protesta como objeto de estudio, sino también asumir un clivaje liberal para su la reflexión, reconduciendo el estudio politológico al ámbito de posibilidades que el liberalismo jurídico ofrece y, que en el caso de la protesta frente al derecho, se presenta en la fórmula típica de un sujeto racional de derechos titular de un derecho a protestar, sin consideración por los elementos conflictivos y antagónicos que la protesta encarna, optando sólo por la libertad individual expresiva para procesar a la protesta en el derecho, teniendo como 
espontáneos y sin una identidad política bien definida. En efecto, la vinculación entre libertad de expresión y protesta es prácticamente casi intuitiva. Ya hemos afirmado que resulta un sinsentido negar la existencia de elementos expresivos en la protesta política, pero también que aquello no puede ser la única respuesta para comprender el conflicto social desde el Derecho.

Ahora bien, podría pensarse que esta recurrente apropiación de la categoría constitucional de la libertad de expresión forma parte de un fenómeno de construcción discursiva con pretensiones de hegemonía desde las estructuras del constitucionalismo. Si se considera que la política como hegemonía pretende totalizar un determinado campo discursivo de significación disponible 68 , es normal pensar que los aparatos del sistema constitucional -entre ellos, la función jurisdiccional creadora de derecho y la doctrina de los pensadores especializados- busquen sentar una cierta racionalidad jurídica y ofrecer criterios que se muestran como objetivos y neutrales, pues ello permite colmar el significado de conceptos espontáneos -como la libertad de expresión en la protesta socialen aquellos fenómenos sociales que aún no han sido alcanzados por la mano civilizadora de la ley.

Se verifica, por tanto, una clausura epistémica, es decir, una cierta producción de "puntos ciegos que protegen arreglos sociales determinados a fin de solidificar la hegemonía que ellos encarnan. En esta tarea desempeñan una labor particularmente importante los operadores epistémicos de la sociedad en cuestión, quienes comparecen en la esfera pública para discutir los grandes problemas sociales: sus intelectuales" ${ }^{\prime 6}$. En este punto cumplen un rol central los operadores jurídicos, especialmente aquellos que, dotados de facultades de creación de Derecho -como pudieren ser los jueces constitucionales en Norteamérica- entregan un discurso oficial sobre lo que verdaderamente significa protestar. Esta construcción jurisprudencial está sostenida en la pretensión de racionalidad del paradigma jurídico moderno, que pretende situarse fuera de los límites de la política, trazando una frontera demarcatoria entre lo que es una reflexión

referencia un supuesto espacio público deliberativo en el que la protesta se inserta y que no pretende socavar, sino más bien reclamar su reconocimiento. Este rasgo liberal del constitucionalismo no es una excepción; Matteucci describe en este punto al constitucionalismo como "el cauce ideal del liberalismo" desde sus orígenes, señala que con el "Estado constitucional el liberalismo heredó también aquellos espacios de libertad, políticamente neutrales o no inmediatamente políticos, que habían nacido o estaban naciendo en su interior: el «mercado» y la «opinión pública» (...) La opinión pública se basa en un intercambio, un intercambio entre individuos racionales, los cuales comunican ideas filosóficas e históricas, morales y religiosas; y, de la misma manera que el mercado era el resultado del intercambio económico de los individuos privados que compiten entre ellos, la opinión pública era el resultado de la comunicación entre individuos singulares que libremente debaten y confrontan sus ideas, que confían sólo en la fuerza de la razón y en la capacidad de persuasión, de ahí la fuerte defensa de la libertad de prensa y de la autonomía de las instituciones culturales, propia de Constant, Kant o Fichte". Al respecto véase MATEUCCI Nicola, Organización del poder y libertad. Historia del constitucionalismo moderno, Valladolid, Trotta, 1998.

68 Este tema puede revisarse de forma detallada, desde una perspectiva del pensamiento radical contemporáneo, en LACLAU Ernesto, BUTLER Judith y ẐIẐEK Slavoj, Contingencia, hegemonía y universalidad. Diálogos contemporáneos en la izquierda, Buenos Aires, Fondo de Cultura Económica, 2004.

${ }^{69}$ MUÑOZ LEÓN Fernando, Hegemonía y Nueva Constitución. Dominación, Subalternidad y Proceso Constituyente, Valdivia, Ediciones UACh, 2016, 35. 
metajurídica y lo que efectivamente implica interpretar y aplicar el Derecho. Volvemos, entonces, al problema de la objetividad en la interpretación constitucional.

Si se considera la clausura epistémica que implica la construcción discursiva de la hegemonía ideológica ${ }^{70}$, la pretensión de objetividad de los intérpretes constitucionales ${ }^{71}$ y la posición institucional de los jueces y su habilitación para producir interpretaciones jurídicas vinculantes ${ }^{72}$, el resultado es una configuración de cierta hegemonía jurídica que opera con algún nivel de coercitividad sobre el conjunto de la sociedad. Aquello es especialmente problemático para la protesta social, pues se trata de la herramienta tradicionalmente utilizada por los grupos subalternos que, gracias a la doctrina del tiempo, lugar y modo, se presenta como una herramienta juridificada, en que la autoridad tendrá facultades para definir cómo se debe protestar y cómo no se debe protestar, neutralizando su potencial en tanto forma de acción política.

\section{Conclusiones}

La doctrina del derecho a la protesta social es una construcción teórica que presenta una doble dimensión: junto con mostrar la cara más amable del derecho frente a la movilización social, podría convertirse, en la mejor herramienta para que la institucionalidad controle los repertorios de movilización a través de las regulaciones neutrales de tiempo, lugar y modo. En este sentido, si bien la idea de justificar a la protesta desde el lenguaje de los derechos -en particular desde la libertad de expresión- puede parecer atractiva, es fundamental considerar que ello también implica aceptar que la protesta podrá ser regulada jurídicamente, en un modo similar al que son regulados otros derechos. El resultado será una protesta juridificada y modelada según el arbitrio de una autoridad política (probablemente, la misma que es impugnada por la protesta). Es clave considerar, entonces, si el rendimiento de la libertad de expresión permite dar cuenta de los fenómenos de protesta social, o si, por el contrario, este tipo de justificación teórica termina por neutralizar aquellas movilizaciones sociales que desbordan la libertad individual e intensifican el contenido reivindicativo de sus discursos.

En este sentido, parece claro que el Derecho carece de las herramientas necesarias para regular una manifestación política cuya finalidad es, precisamente, cuestionar las mismas formas jurídicas que condicionan el ejercicio de los derechos o de la acción política propiamente tal. Así, configurar el derecho a la protesta social desde la doctrina del tiempo, lugar y modo bien podría ser funcional a los intereses de la autoridad política cuestionada, por cuanto genera las condiciones institucionales que hacen posible la neutralización de su dimensión conflictual al contener el impacto de sus discursos disruptivos. Frente a la interrogante sobre el papel que podría cumplir el Derecho ante la protesta social, podríamos identificar tres posibilidades: 1. como una herramienta de

\footnotetext{
70 MUÑOZ LEÓN, op. cit.

71 BASSA MERCADO Jaime, “La pretensión de objetividad como estrategia para obligar. La construcción de cierta cultura de hermenéutica constitucional hacia fines del siglo XX", en Estudios Constitucionales (Año 11, $\mathrm{N}^{\mathrm{o}}$ 2, 2013), Santiago, 15-46.

72 KENNEDY, op. cit.
} 
decisión judicial, en términos similares de Hague v. CIO, o, en Chile, en el caso Llaguel Figueroa y otros con Ilustre Municipalidad de Santiago, es decir, que juzgue la proporcionalidad de las regulaciones estatales a la protesta; 2. como un eventual criterio de regulación normativa que le entregue contenido al derecho a protestar, limitando el derecho a protestar; y 3. como una herramienta para juzgar una especie de deber correlativo del derecho a protestar, por el cual quienes se articulan para manifestarse deben hacerlo siempre respetando los límites impuestos por el derecho.

Sin embargo, la libertad de expresión, en tanto derecho fundamental de matriz antropológica individualista, no permite procesar adecuadamente la dimensión colectiva de la protesta, así como tampoco la potencia de aquellas formas políticas que evidencian un conflicto social marcado por reivindicaciones sociales, las que se formulan no solo contra la autoridad, sino contra el propio ordenamiento jurídico. Se trata de una doble limitación que evidencia los límites epistémicos de esta aproximación desde el derecho a la libertad de expresión: la dimensión colectiva que desborda el contenido individual del derecho fundamental y la dimensión política de su contenido, que se sitúa más allá de los límites del discurso jurídico. En razón de lo anterior, la libertad de expresión no puede ser utilizada para justificar a la protesta frente al Derecho, pues, ante todo, así como la protesta pretende reclamar la atención de la autoridad, también busca impugnar, mediante la articulación de prácticas disruptivas, aquella posición de poder con que cuenta la autoridad para el ejercicio del poder político. De alguna manera, recurrir a las categorías conceptuales del paradigma jurídico moderno para procesar institucionalmente ciertas manifestaciones del conflicto social es una forma de higienizar la relación entre derecho y política, al ocultar la tensión permanente que significa el ordenamiento jurídico para la configuración y conservación de determinada estructura de relaciones de poder. Toda protesta social se levanta contra alguna manifestación de dichas estructuras, buscando terminar con ellas o con las prácticas sociales que ellas hacen posible. Eso por eso que procesar dicha protesta a través de normas jurídicas que, en última instancia, se encuentran entrelazadas con esas mismas estructuras de poder, supone neutralizar el acto de protesta y contener su potencial de transformación social.

\section{Bibliografía citada}

\section{Artículos y libros}

ARDITI Benjamín, La política en los bordes del liberalismo. Diferencia, populismo, revolución, empancipación, Barcelona, Editorial Gedisa, 2011.

BASSA MERCADO Jaime, "La pretensión de objetividad como estrategia para obligar. La construcción de cierta cultura de hermenéutica constitucional hacia fines del siglo XX", en Estudios Constitucionales (Año 11, No 2, 2013), 15-46.

BRION Fabienne y HARCOURT Bernard, "Situación del curso", en Michel Foucault, Obrar mal, decir la verdad. La función de la confesión en la justicia. Curso de Lovaina, Buenos Aires, Siglo XXI Editores, 2014, 281-340. 
BUTLER Judith, “«Nosotros, el pueblo». Apuntes sobre la libertad de reunión”, en ¿Qué es un pueblo?, Santiago, Editorial LOM, 2014, 41-59.

CELIKATES Robin, "Rethinking civil disobedience as a practice of social contestation. Beyond the liberal paradigm", en Constellations (Vol. 23, No 1, 2016), 37-45.

CRUZ PARCERO Juan Antonio, El lenguaje de los derechos. Ensayo para una teoría estructural de los derechos, Madrid, Editorial Trotta, 2007.

DELLA PORTA, Donatella; DIANI, Mario, Social movements. An introduction, Oxford, Blackwell Publishing, 2006.

ELSTER Jon y SLAGSTAD Rune, Constitucionalismo y democracia, México D.F., Editorial Fondo de Cultura Económica, 1999.

FERRAJOLI Luigi, Garantismo. Una discusión sobre derecho y democracia, Madrid, Editorial Trotta, 2009.

FISS Owen, Democracia y Disenso. Una teoría de la libertad de expresión, Buenos Aires, Editorial Ad Hoc, 2010.

FOUCAULT Michel, La verdad y las formas jurídicas (Traducc. Linch Enrique), Barcelona, Editorial Gedisa, 2011.

FOUCAULT Michel, Obrar mal, decir la verdad. La función de la confesión en la justicia. Curso de Lovaina (Traducc. Horacio Pons), Buenos Aires, Siglo XXI Editores, 2014.

GARGARELLA Roberto, El derecho a la protesta. El primer derecho, Buenos Aires, Editorial Ad Hoc, 2007.

GARGARELLA Roberto, "Un diálogo sobre la protesta social y la ley", en Revista de la Facultad de Derecho (No 61, 2008) Lima, Pontificia Universidad Católica del Perú, 1950.

GARGARELLA Roberto, Carta abierta sobre la intolerancia. Apuntes sobre derecho y protesta, Buenos Aires, Siglo XXI Editores, 2015.

GARGARELLA Roberto, "Prólogo: Derecho a la protesta: pensarlo todo de nuevo", en Criminalización de la protesta. La respuesta del Estado frente a los reclamos ciudadanos, Buenos Aires, Editorial Ad Hoc, 2015a, 11-18.

GONZÁLEZ CALLEJA Eduardo, Asalto al poder. La violencia politica organizada y las ciencias sociales, Madrid, Siglo XXI, 2017.

GONZÁLEZ Horacio, "La resistencia al derecho", en El derecho a resistir el derecho, Buenos Aires, Miño y Dávila Editores), 2005, 117-120.

GRAMSCI Antonio, Antología, Madrid, Akal, 2015.

KENNEDY Duncan, Izquierda y derecho. Ensayos de teoría jurídica crítica, Buenos Aires, Siglo XXI Editores, 2010.

LACLAU Ernesto; BUTLER Judith y ẐIẐEK Slavoj, Contingencia, hegemonía y universalidad. Diálogos contemporáneos en la izquierda, Buenos Aires, Fondo de Cultura Económica, 2004.

LORENZO CADARSO Pedro, Fundamentos teóricos del conflicto social, Madrid, Siglo XXI, 2001.

LOVERA Domingo, “ ¿Tres son multitud? Constitucionalismo Popular, Cortes y Protesta”, [En línea], [fecha de consulta: 9 de febrero de 2018]. [Disponible en: https://www.academia.edu/7933336/_Tres_son_Multitud_Constitucionalismo_po pular_cortes_y_protesta] 
LOVERA Domingo, "Libertad de expresión, derecho de reunión y protesta en la Constitución", en La Constitución chilena. Una revisión crítica a su práctica política, Santiago, Editorial LOM, 2015, 99-119.

MATEUCCI Nicola, Organización del poder y libertad. Historia del constitucionalismo moderno, Valladolid, Trotta, 1998.

MILLAS Jorge, Filosofía del Derecho, Santiago, Ediciones UDP, 2010.

MONTONI RÍOS Ángelo, "Movimientos sociales y violencias colectivas; factores explicativos desde la frustración relativa", Actuel Marx ( $\left.\mathrm{N}^{\mathrm{o}} 13,2012\right), 41-63$.

MOUFFE Chantal, Política y pasiones. El papel de los afectos en la perspectiva agonista, Valparaíso, Editorial Universidad de Valparaíso, 2016.

MUJICA Pedro, Poder en disputa. Partidos politicos, grupos de interés y movimientos sociales, Santiago, Ediciones Universidad Alberto Hurtado, 2014.

MUÑOZ LEÓN Fernando, Hegemonía y Nueva Constitución. Dominación, Subalternidad y Proceso Constituyente, Valdivia, Ediciones UACh, 2015.

O'NEILL Kevin, "Disentangling the law of public protest", en Loyola Law Review (Vol. 45, 1999), 411-526.

PISARELLO Gerardo, Un largo termidor. Historia y crítica del constitucionalismo antidemocrático, Quito, Corte Constitucional para el Período de Transición, 2012

RANCIÈRE Jacques, El reparto de lo sensible, Santiago, Editorial LOM, 2009.

RAZ Joseph, The Morality of Freedom, Oxford, Oxford University Press, 1988.

REX John, El conflicto social, Madrid, Siglo XXI de España Editores, 1985.

SANDOVAL Daniel, "El Estado democrático de derecho en términos de dominación: justicia constitucional y violencia simbólica", en Alegatos, (Nº3, 2013), 31-54.

SCRIBANO Adrian, "Reflexiones sobre una estrategia metodológica para el análisis de las protestas sociales", en Sociologías, (No 9, 2003), 64-104.

TARROW Sidney, Power in movement. Social movements and contentious politics, New York, Cambridge University Press, 2011.

TILLY Charles, Los movimientos sociales, 1768-2008. Desde sus orígenes a Facebook, (Traducción: Esteve Ferrán), Barcelona, Editorial Crítica, 2010.

TOLLER Fernando, El formalismo en la libertad de expresión. Crítica de la distinción absoluta entre restricciones previas y responsabilidades ulteriores, Madrid, Marcial Pons, 2011.

ZIBECHI Raúl, Dispersar el poder. Los movimientos como poderes antiestatales, Santiago, Editorial Quimantú, 2007.

ŽIŽEK Slavoj, En defensa de la intolerancia, Madrid, Ediciones Sequitur, 2008.

\section{Jurisprudencia}

Capitol Square Review and Advisory Bd. v. Pinette (1995): Suprema Corte de los Estados Unidos de América, 515 U.S. 753 (1995), [En línea], [Fecha de consulta 9 de febrero de 2018], [Disponible en:

https://supreme.justia.com/cases/federal/us/515/753/case.html]

Clark v. Community for Creative Non Violence (1984): Suprema Corte de los Estados Unidos de América, 468 U.S. 288, [En línea], [Fecha de consulta 9 de febrero de 2018]. [Disponible en: https:/ / www.law.cornell.edu/supremecourt/text/468/288] 
Cox v. Lousiana (1965): Suprema Corte de los Estados Unidos de América, 379 U.S. 536, [En línea], [Fecha de consulta: 9 de febrero de 2018], [Disponible en: https://supreme.justia.com/cases/federal/us/379/536/case.html]

Hague v. Committee for Industrial Organization (1939): Suprema Corte de los Estados Unidos de América, 307 U.S. 496, [En línea], [Fecha de consulta 9 de febrero de 2018]. [Disponible en: https://supreme.justia.com/cases/federal/us/307/496/case.html]

Llaguel Figueroa Carlos y otros con Ilustre Municipalidad de Santiago (2014): Sentencia de la Corte de Apelaciones de Santiago, Recurso de Protección, Rol No 39022- 2014, [En línea], [Fecha de consulta: 9 de febrero de 2018]. [Disponible en: http:/ / www.comunidadyjusticia.cl/attachments/article/299/SENTENCIA\%20PRO TECCION\%20TOMAS\%20COLEGIOS.pdf]

Ward v. World Against Racism (1989): Suprema Corte de los Estados Unidos de América, 491 U.S. 781, [En línea], [Fecha de consulta 9 de febrero de 2018], [Disponible en: https://supreme.justia.com/cases/federal/us/491/781/case.html] 